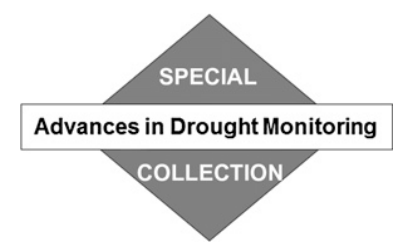

\title{
Dynamical Causes of the 2010/11 Texas-Northern Mexico Drought*
}

\author{
RICHARD SEAGER \\ Lamont Doherty Earth Observatory of Columbia University, Palisades, New York \\ LISA GODDARD \\ International Research Institute for Climate and Society, Palisades, New York \\ Jennifer NakAmura, NAOmi Henderson, AND Dong Eun LeE \\ Lamont Doherty Earth Observatory of Columbia University, Palisades, New York
}

(Manuscript received 29 January 2013, in final form 19 September 2013)

\begin{abstract}
The causes of the Texas-northern Mexico drought during 2010-11 are shown, using observations, reanalyses, and model simulations, to arise from a combination of ocean forcing and internal atmospheric variability. The drought began in fall 2010 and winter 2010/11 as a La Niña event developed in the tropical Pacific Ocean. Climate models forced by observed sea surface temperatures (SSTs) produced dry conditions in fall 2010 through spring 2011 associated with transient eddy moisture flux divergence related to a northward shift of the Pacific-North American storm track, typical of La Niña events. In contrast the observed drought was not associated with such a clear shift of the transient eddy fields and instead was significantly influenced by internal atmospheric variability including the negative North Atlantic Oscillation of winter 2010/11, which created mean flow moisture divergence and drying over the southern Plains and southeast United States. The models suggest that drought continuation into summer 2011 was not strongly SST forced. Mean flow circulation and moisture divergence anomalies were responsible for the summer 2011 drought, arising from either internal atmospheric variability or a response to dry summer soils not captured by the models. The summer of 2011 was one of the two driest and hottest summers over recent decades but it does not represent a clear outlier to the strong inverse relation between summer precipitation and temperature in the region. Seasonal forecasts at 3.5-month lead time did predict onset of the drought in fall and winter 2010/11 but not intensification into summer 2011, demonstrating the current, and likely inherent, inability to predict important aspects of North American droughts.
\end{abstract}

\section{Introduction}

In the fall of 2010 the U.S. Drought Monitor showed no areas of the United States in drought, a situation essentially unique since the Drought Monitor was initiated in 1999. However, even as the Drought Monitor was showing unusually moist conditions across the country, seasonal-to-interannual forecasts were predicting a

\footnotetext{
* Lamont Doherty Earth Observatory Contribution Number 7742.

Corresponding author address: Richard Seager, Lamont Doherty Earth Observatory of Columbia University, 61 Route 9W, Palisades, NY 10964.

E-mail: seager@ldeo.columbia.edu
}

return to dry conditions across the southern United States and northern Mexico in the winter ahead. Those forecasts were based on predictions of a developing $\mathrm{La}$ Niña in the tropical Pacific Ocean. Historically La Niña events have led to drier than normal conditions in the southwest United States, northern Mexico, the southern Plains, and southeast United States and wetter than normal conditions in the Pacific Northwest (Ropelewski and Halpert 1986; Mason and Goddard 2001; Seager et al. 2005a). This turned out to be a good forecast for much of the southern United States in winter 2010/11, which experienced drier than normal conditions except in Southern California.

The interior southwestern states of the United States receive most of their precipitation in the winter and hence this was sufficient to move those states back 
toward abnormal dryness or drought. In Texas, precipitation has a major peak in spring and a minor peak in fall, with drier winters. There, the dry winter of 2010/11 was followed by a dry spring and a dry summer, which, in sum, were sufficient to cause one of the most catastrophic short-term droughts in U.S. history (NielsenGammon 2012). As is usually the case, dry conditions in the southern Plains went along with higher than normal temperatures and Texas and surrounding regions in summer 2011 broke records for the warmest summer on record. The costs in terms of U.S. agricultural losses were staggering. The National Climatic Data Center estimated it at $\$ 12$ billion (http://www.ncdc.noaa.gov/ billions/events.pdf). The Texas drought, combined with the spring 2011 tornado season, floods in the Mississippi basin, and Hurricane Irene, made 2011 the costliest year to date in terms of weather- and climate-related disasters, reemphasizing the vulnerability of the United States to extreme weather and climate events. Meanwhile, in Mexico in November 2011 the Secretary for Social Development reported that drought had left 2.5 million Mexicans with insufficient drinking water (http:// www.radioformula.com.mx/notas.asp?Idn=210675) and shortages of basic foodstuffs led to a large increase in imports from the United States (http://www.mnoticias. com.mx/note.cgi?id=403006). Mexico has been suffering a drought since the mid-1990s (Seager et al. 2009; Stahle et al. 2009) so the severity of the 2011 drought further revealed the climatic vulnerability of Mexico.

This paper focuses on the Texas-northern Mexico (hereafter TexMex) drought and addresses the question of what caused it. This is an important question in that it has been argued that anthropogenic global warming should lead to aridification of the subtropics and a poleward expansion of subtropical dry zones (Solomon et al. (2007); Seager et al. 2010b; Cayan et al. 2010) and also a shift to more extreme precipitation events. Was the TexMex drought a case of such anthropogenically induced climate change? It would certainly be rash to draw such a conclusion given that past droughts in the U.S. Southwest and Plains have been reliably attributed to forcing of atmospheric circulation anomalies by naturally occurring cool tropical Pacific and, to a lesser extent, warm tropical North Atlantic sea surface temperature (SST) anomalies (Schubert et al. 2004a,b; Seager et al. 2005b; Herweijer et al. 2006; Seager 2007). This most recent drought also coincided with a La Niña event. Indeed, a recent study (Hoerling et al. 2013) has concluded that the precipitation reduction over Texas in the summer of 2011 was within the range of natural variability of the atmosphere-ocean-land surface system and made much more likely by the La Niña of
2010/11 but that anthropogenic climate change contributed to the record-breaking high temperatures.

While the 2010/11 drought and heat wave was decidedly severe, much longer droughts have occurred. The records that were broken during the event were often set in the 1930s and 1950s during two devastating multiyear droughts created by some mix of tropical Pacific and Atlantic SST variations and internal atmospheric variability and, for the 1930s Dust Bowl drought, dust aerosol forcing (Schubert et al. 2004a,b; Seager et al. 2005b, 2008; Cook et al. 2008, 2009, 2010; Hoerling et al. 2009). By the standards of those droughts, or some nineteenth-century droughts (Stahle and Cleaveland 1988; Herweijer et al. 2006), the 2010/11 drought was intense but brief. However, after a relatively wet winter in 2011/12, especially in eastern Texas, and a severe drought in summer 2012 in the central United States and Midwest (Hoerling et al. 2014), drought has persisted in the TexMex region to the present (November 2013), so this event is not yet over.

In this paper, we focus on the dynamical causes of the 2010/11 TexMex drought in terms of circulation anomalies and variations of surface evaporation and transports and convergence of moisture within the atmosphere and examine its evolution from fall of 2010 to its most extreme state in summer and fall of 2011. Our goal is to determine the ocean-atmosphere dynamics of this event and, by reference to prior work, assess how similar or different it was to other droughts in the region and the typical seasonal-to-interannual variability of hydroclimate in the region forced by the tropical oceans. As part of this effort, we will examine how well the drought can be reproduced in atmosphere models forced by the observed SSTs and, hence, the potential predictability of the event. In addition we will examine how well the event was actually forecast in advance, which depended on the ability to forecast the SSTs and the atmospheric response to them and any atmospheric response to prior land surface conditions.

A comprehensive analysis and understanding of the 2010/11 TexMex drought, and its predictability, will inform decision making and disaster planning by allowing assessment of its likelihood, advance warning signs, and ability to predict ahead of time, or lack thereof.

\section{Observational and model data}

The observed precipitation data are from the National Oceanic and Atmospheric Administration (NOAA) National Centers for Environmental Prediction (NCEP) Climate Prediction Center (Chen et al. 2002) available from the Data Library of the International Research Institute for Climate and Society (http://iridl.ldeo.columbia.edu) 
and covering 1948 to the present. For the analyses of observed SST, atmospheric circulation, and surface air temperature we use data from the NCEP-National Center for Atmospheric Research (NCAR) reanalysis covering 1949 to present (Kalnay et al. 1996; Kistler et al. 2001).

The first model used is the NCAR Community Climate Model version 3 (CCM3), which has been used extensively by us for North American drought research (e.g., Seager et al. 2005b). NCAR has released many atmosphere models since CCM3 and all have been experimented with at Lamont Doherty Earth Observatory but none found to be as skillful at reproducing the observed history of southwest North American and Plains precipitation as CCM3. Hence, despite its vintage, we use CCM3 here. The model is forced by observed SSTs that are from the Kaplan et al. (1998) data in the tropical Pacific Ocean and the Hadley Centre data (Rayner et al. 2003) elsewhere. Sixteen ensemble members were generated with different initial conditions and results are primarily shown for the ensemble mean, which averages over uncorrelated weather in the members and closely isolates the common SST-forced component. The simulations begin on 1 January 1856. Unlike in Seager et al. (2005b), the simulations here also have the observed increases in $\mathrm{CO}_{2}$ and $\mathrm{CH}_{4}$ imposed allowing land surfaces to warm and the atmospheric circulation to adjust to the changes in radiative properties. The other model is the European Centre-Hamburg model, version 4.5 (ECHAM4.5; Roeckner et al. 1996), and we use a 24-member ensemble from 1950 on available in the International Research Institute for Climate and Society Data Library (http://iridl.ldeo.columbia.edu/SOURCES/ .IRI/.FD/.ECHAM4p5/.History/.MONTHLY/).

We also use the NCEP-NCAR reanalysis and the Interim European Centre for Medium-Range Weather Forecasts (ECMWF) Reanalysis (ERA-Interim, herein ERA-I; Dee et al. 2011) datasets to evaluate the components of the moisture budget that caused precipitation anomalies during the drought. For both reanalyses we evaluate anomalies of the convergence or divergence of the vertically integrated moisture transports by (i) the mean flow and (ii) the transient flow. The former is evaluated using monthly mean values of winds and specific humidity and the latter using covariances of departures of submonthly values from the monthly means. The NCEP-NCAR reanalysis provided the covariances and for ERA-I, they were evaluated with 6-hourly data. The vertical integrals extend to the monthly mean surface pressure using eight standard pressure levels for NCEP and 26 levels for ERA-I. Evaluating the moisture budget diagnostically from reanalysis data leads to errors compared to the actual moisture budget calculation in the models that produce the reanalyses due to differences in the numerical methods used and the time and vertical resolutions of the calculation. Nonetheless, as shown in Seager and Henderson (2013), when care is taken to adopt the best computational methods, as we do here, diagnostic evaluation of moisture budget components can produce useful results.

Anomalies shown here are computed relative to the period that is common to all the models and observations, January 1950 to November 2011. The only exception is for the ERA-I, which begins in 1979 and for which we assess anomalies relative to a 1979 to 2011 climatology.

\section{Typical La Niña-associated precipitation and circulation anomalies in the Pacific-North American region}

Since the 2010/11 drought was associated with full and then waning La Niña conditions we first of all review the typical precipitation and circulation anomalies in the Pacific-North American region associated with La Niñas for later comparison with what happened during the 2010/11 event. This was done based on the Niño-3 index (SST anomalies averaged over $5^{\circ} \mathrm{S}-5^{\circ} \mathrm{N}, 130^{\circ}-$ $90^{\circ} \mathrm{W}$ ), which was formed into December-February (DJF), March-May (MAM), June-August (JJA), and September-November (SON) seasonal anomalies. The years when the anomaly values were less than one standard deviation were then identified. Values of observed SST, and observed and modeled precipitation and 200-mb height, were then composited for these years to provide seasonal values of typical La Niña conditions. ${ }^{1}$

\section{a. Observed canonical La Niña conditions}

SST anomalies are well developed in SON and go along with a high anomaly over the midlatitude west Pacific and North America, with a low anomaly in between over the Pacific Northwest, and dry anomalies across the United States and Mexico from Southern California to the Atlantic (Fig. 1). The classic ENSO pattern is clear in DJF with a cyclonic anomaly immediately north of the cold tropical Pacific SST anomaly,

\footnotetext{
${ }^{1}$ The years and seasons identified as La Niñas were 1950 (MAM, JJA, SON), 1955 (SON), 1956 (JJA), 1964 (JJA, SON), 1970 (JJA, SON), 1971 (MAM, JJA, DJF), 1973 (JJA, SON), 1974 (MAM, JJA, DJF), 1975 (MAM, JJA, SON), 1976 (MAM, DJF), 1985 (DJF), 1988 (JJA, SON), 1989 (MAM, DJF), 1999 (all seasons), 2000 (MAM, DJF), 2007 (SON), 2008 (MAM, DJF), 2010 (JJA, SON), and 2011 (MAM, DJF) where DJF 2011 indicates DJF 2010/11, for example. The two models used different SST datasets and, in particular, have some additional La Niña seasons in 1954, 1955, and 1956.
} 
a) $\mathrm{SON}$

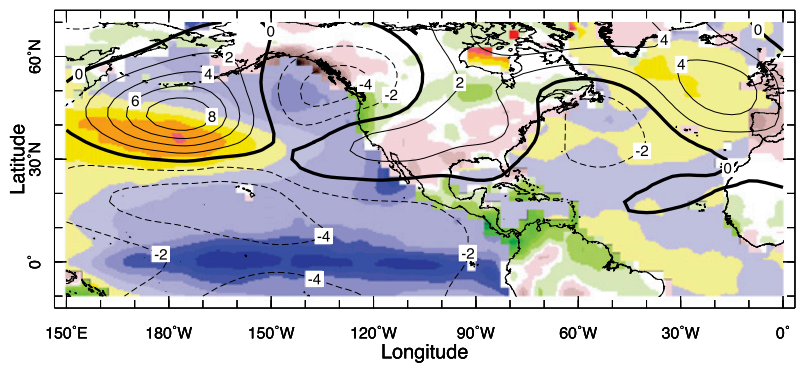

c) MAM

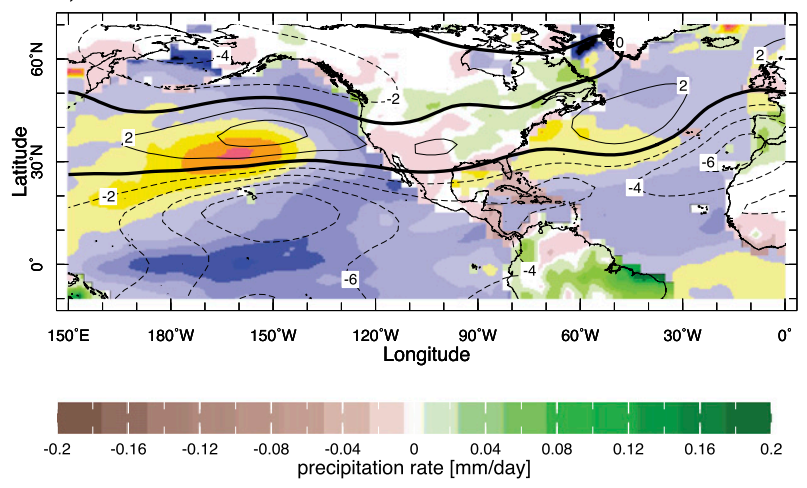

b) DJF

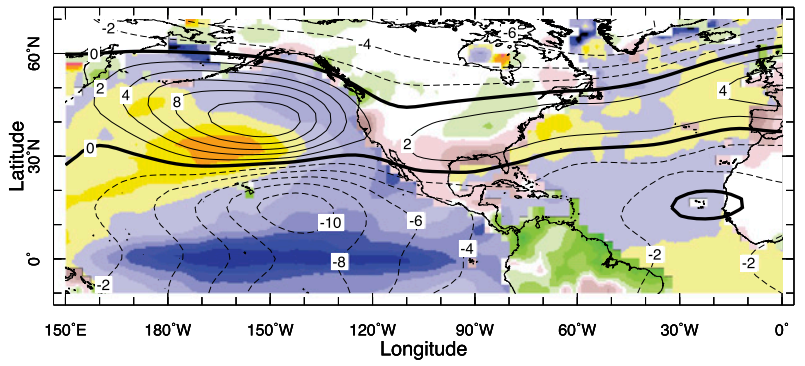

d) JJA

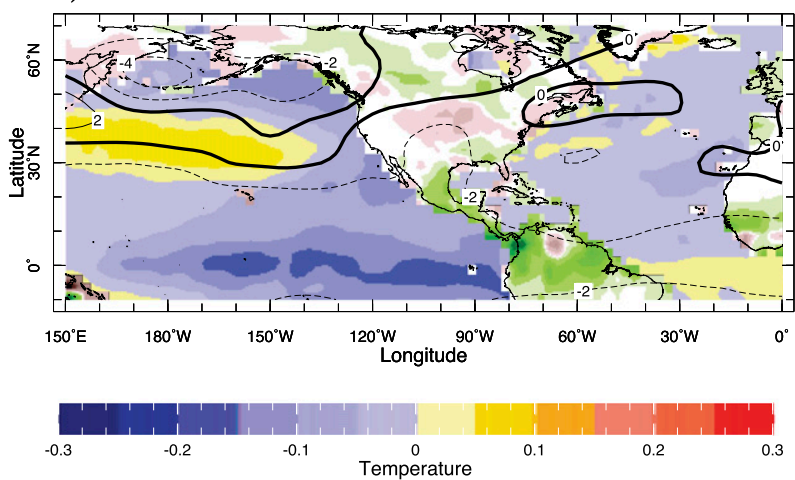

FIG. 1. The observed SST, precipitation (over land only), and 200-mb heights composited over La Niña events by season. Units are degrees Kelvin, mm month ${ }^{-1}$, and geopotential meters, respectively.

a well-developed North Pacific high anomaly that merges with a zonal band of high pressure over North America and the midlatitude Atlantic Ocean. Dry conditions extend across Mexico and the southern portions of the United States with a maximum at the Gulf coast. La Niña SST anomalies are typically weaker in MAM and so are the circulation and precipitation anomalies. Even though the SST anomalies remain in JJA, the circulation anomalies are weak, consistent with our understanding of the seasonal cycle of tropical to midlatitude teleconnections (Kumar and Hoerling 1998).

\section{b. Modeled canonical La Niña conditions}

The models use different SST datasets from that used for the SST anomalies shown in Fig. 1 but the differences are very small. CCM3 shows a typical La Niña height response from SON through MAM with a ridge extending from the North Pacific to the midlatitude Atlantic with a localized high somewhere over North America in each season (Fig. 2). This is also the case for ECHAM4.5 (Fig. 3) but with the SON anomalies weaker, and the DJF anomalies stronger, than in CCM3. The SON La Niña precipitation anomalies in both models show wet in the Pacific Northwest and dry across most of the rest of the continent as observed (Fig. 1). The observed northsouth wet-dry La Niña dipole in DJF is best modeled by ECHAM4.5 whereas CCM3 continues with the wet
Pacific Northwest and dry everywhere else pattern seen in SON. CCM3 produces widespread dry anomalies in MAM and JJA of La Niñas in contrast to the more spatially variable observed La Niña precipitation anomalies in these seasons. ECHAM4.5 produces MAM precipitation anomalies that are far too strong but have some of the observed pattern with dry conditions in the southwest. ECHAM4.5 also produces far too extensive dry conditions over the United States and Canada in La Niña JJAs but does capture the wet conditions in Mexico and Central America.

\section{SSTs during the 2010/11 TexMex drought}

Returning to the specific case of 2010/11, Fig. 4 shows the history of sea surface temperature and surface air temperature over land during the drought. In fall (SON) of 2010 a strong La Niña had already developed with anomalies of around $-2^{\circ} \mathrm{C}$ while the tropical Atlantic Ocean was warmer than normal. The La Niña was still strong in winter (DJF) 2010/11 and the SST anomalies in both oceans then weakened through spring (MAM) and summer (JJA) of 2011. By summer of 2011 the La Niña was essentially gone and the tropical Atlantic SST anomalies were also weak. The La Niña began to reform in fall of 2011 (and developed into another La Niña for winter 2011/12; not shown). Temperatures over North 
a) $\mathrm{SON}$

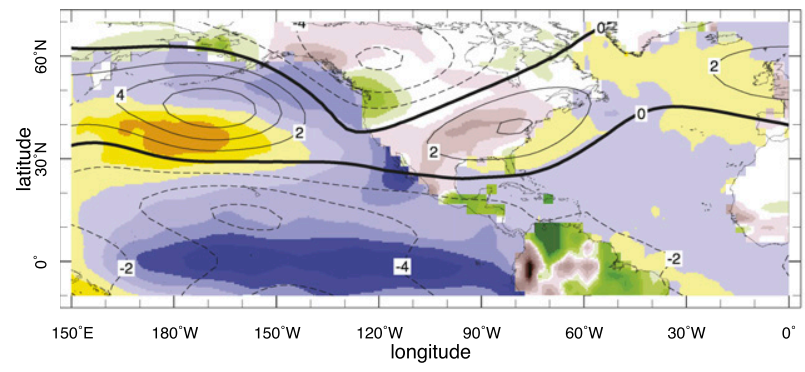

c) MAM
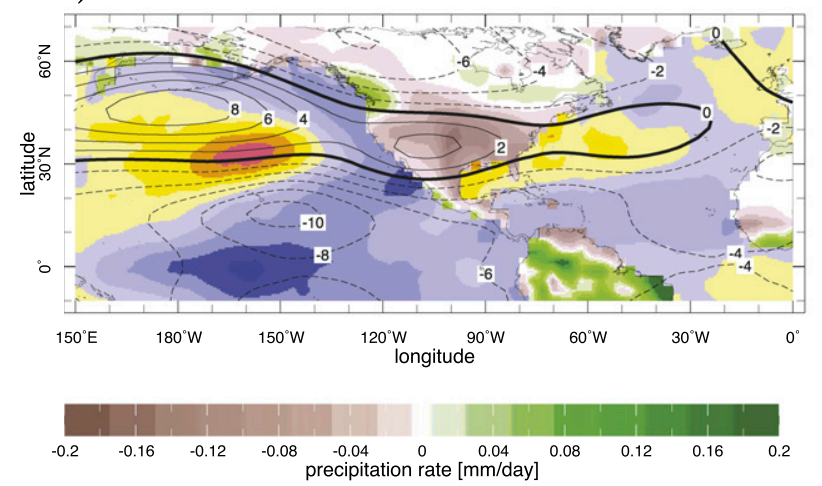

b) DJF

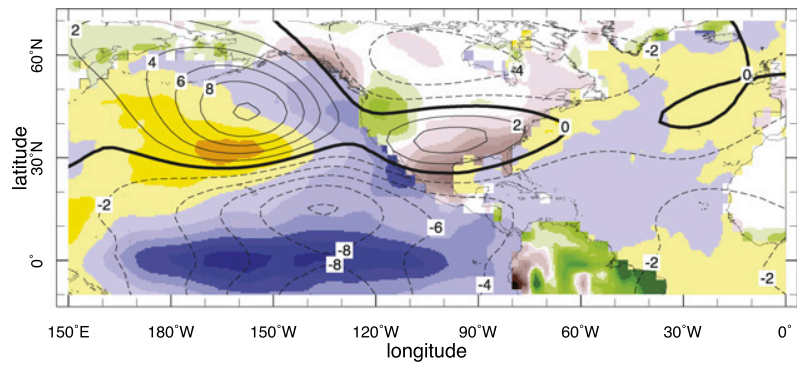

d) JJA

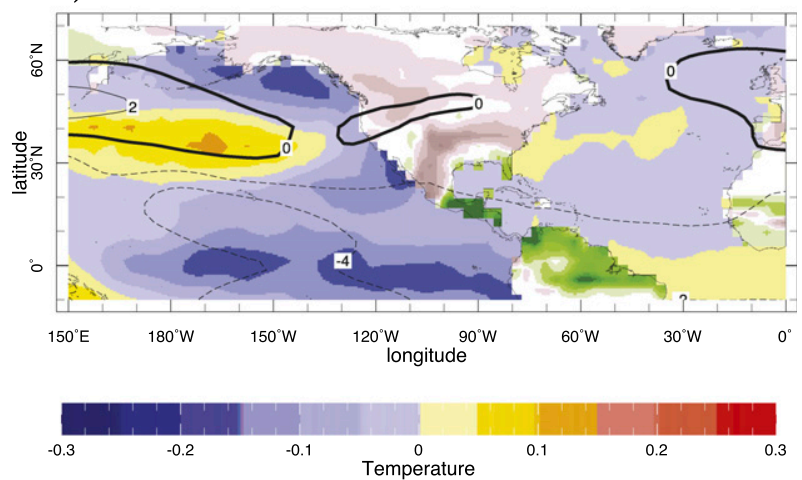

FIG. 2. As in Fig. 1, but for the CCM3 model simulations.

America were actually colder than normal in winter 2010/11, especially in the eastern United States. Anomalous heat developed in Mexico, the southern and central Plains, and the Southeast in spring 2011 and maximized in the summer with a bull's-eye centered on the central Plains and extending over northern Mexico and the entire eastern United States. The fall 2010 and winter 2010/11 SST patterns would be expected to force dry conditions across the southern United States as a response to both the cold tropical Pacific SSTs and the warm tropical North Atlantic SSTs, an ideal configuration for forcing North American drought (Schubert et al. 2009). Tropical Pacific SST anomalies are known to be quite predictable on the seasonal-to-interannual time scale (e.g., Jin et al. 2008) so it would also be expected that the component of the drought forced from the tropical Pacific could be predicted several months ahead of time. However, the continuation and intensity of the drought in summer and fall 2011 is hard to reconcile with contemporaneous SST forcing since the SST anomalies are weak by that season.

\section{Comparison of observed and model-simulated precipitation anomalies during the TexMex drought}

Figure 5 shows for 3-month seasons beginning in September to November 2010 and ending in September to November 2011 the observed precipitation anomalies and those modeled by the CCM3 and ECHAM4.5 models when forced by the observed SSTs. The actual precipitation anomaly was consistently negative across Texas and Mexico and much of the surrounding states throughout this entire 15-month period. Dry anomalies were modest in fall 2010 but were in full force in DJF 2010/11 and centered in the southeast, strong and centered in Mexico and the south-central United States in MAM 2011, and then intensified and spread into JJA 2011. In SON 2011 most of the west and central United States was also dry while the Midwest and Northeast were very wet. From SON 2010 to MAM 2011 the observed precipitation anomalies have some similarity with those typical for La Niña conditions during those seasons (Fig. 2) but the strong summer drying is not typical.

The models simulate widespread dry conditions across most of the United States and Mexico in fall 2010 and the southern United States and Mexico in winter 2010/11. These model patterns are quite similar to those observed except over California where the models simulated dry conditions as a typical model La Niña response (Figs. 3 and 4) but, in fact, a wet fall 2010 and winter 2010/11 actually occurred. In MAM 2011 the models simulate dry conditions across most (CCM3) or all (ECHAM4.5) of Mexico and almost all of the United States and fail to reproduce the north-south wet-dry dipole actually 
a) $\mathrm{SON}$

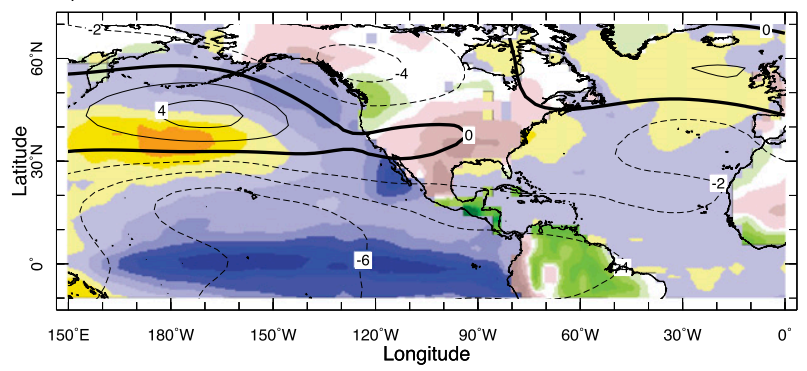

c) MAM

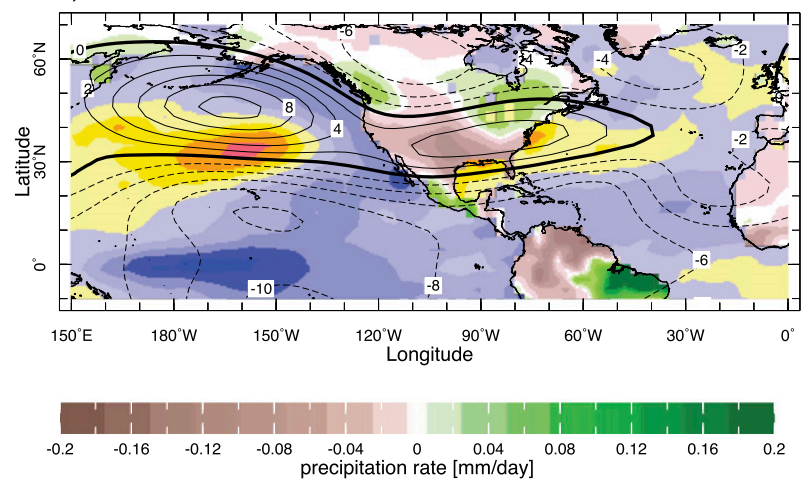

b) DJF

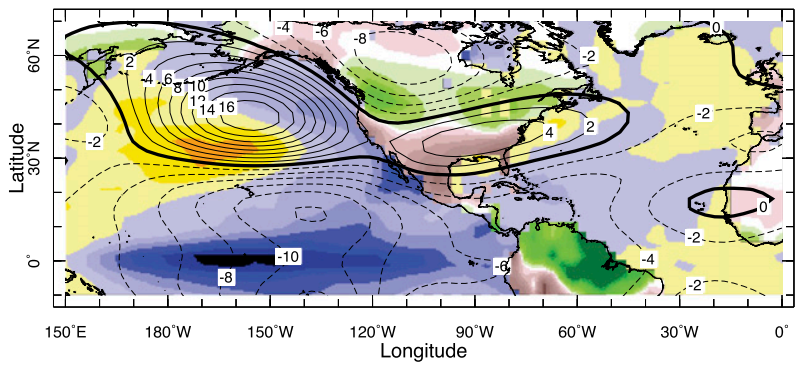

d) JJA

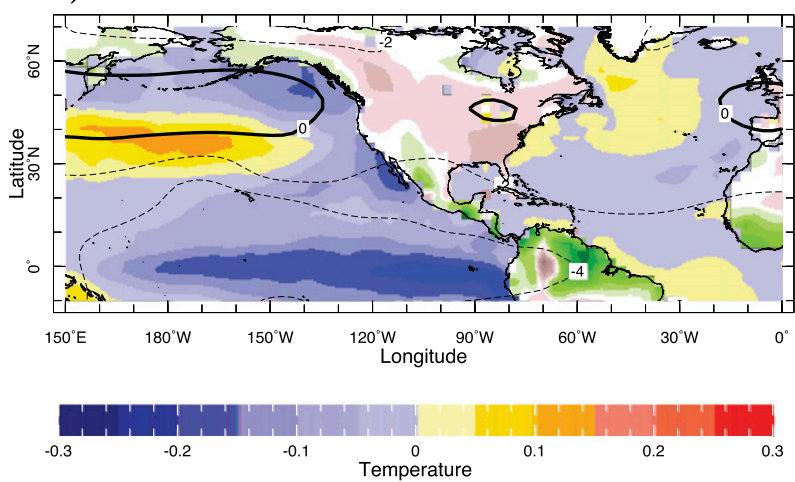

FIG. 3. As in Fig. 1, but for the ECHAM4.5 model simulations.

observed, although ECHAM4.5 does simulate the wet Midwest and Northeast that was observed. The model precipitation anomalies in MAM 2011 are similar to their canonical La Niña responses. After spring, as the La Niña faded away, the models do not reproduce the focused and strong northern Mexico-Texas drought in summer and fall 2011. However, ECHAM4.5 does produce widespread but modest drying across the United States and northern Mexico. Hoerling et al. (2013) show results for June through August for SST forcing of the atmosphere model component of NOAA's Climate Forecast System version 2. That model produces drying only half as strong as that observed and also not focused in the TexMex area. The results from these models indicate that 1) the beginning of the drought in fall 2010 and winter 2010/11 was related to the development of SST anomalies and 2) the intensity of the drought in summer and fall 2011 was not uniquely a response to SST anomalies.

Table 1 lists the area-weighted anomaly correlation coefficients between observed and modeled precipitation anomalies for land areas between $20^{\circ}$ and $50^{\circ} \mathrm{N}$ providing a quantitative measure to go with the description above. ECHAM4.5 performs better than CCM3, especially in MAM and JJA 2001, the models are very similar in the DJF 2010/11 precipitation patterns and both have similarity to the observed pattern (all reflecting similar patterns of response to SST forcing) and the models fail to reproduce the observed pattern in SON 2011.

\section{Causes of the 2010/11 TexMex drought: Modeled and reanalyzed moisture budget anomalies}

\section{a. Modeled moisture budget anomalies}

The two atmosphere models used here, together with the two reanalyses, provide some indication of the causes of the drought and hence we analyze the variations in the atmospheric branch of the hydrological cycle within the models to determine how changes in evaporation and moisture convergence by the mean and transient flow combined to generate lower than normal precipitation. Figures 6-10 show anomalies in modeled precipitation minus evaporation that in the atmosphere, balance the convergence of vertically integrated moisture transport and at the surface, balance soil moisture tendency and surface and subsurface runoff. Also shown are evaporation and the mean flow and transient eddy contributions to the convergence of vertically integrated moisture transport, all for the seasons from fall 2010 through fall 2011.

In SON 2010 (Fig. 6) the reduction of precipitation simulated by both the CCM3 and ECHAM4.5 models is 
SON 2010

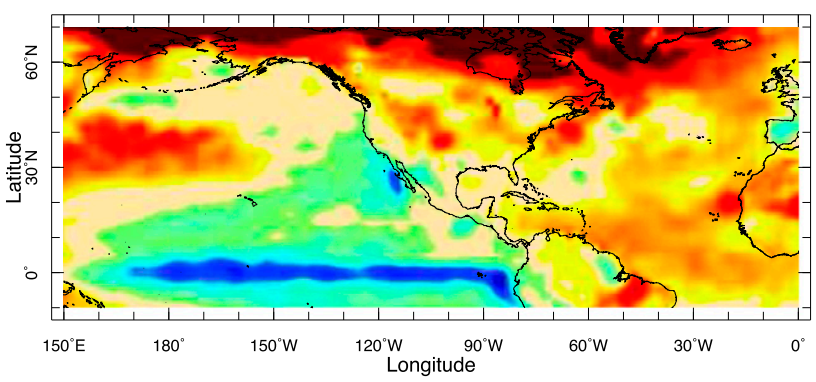

MAM 2011

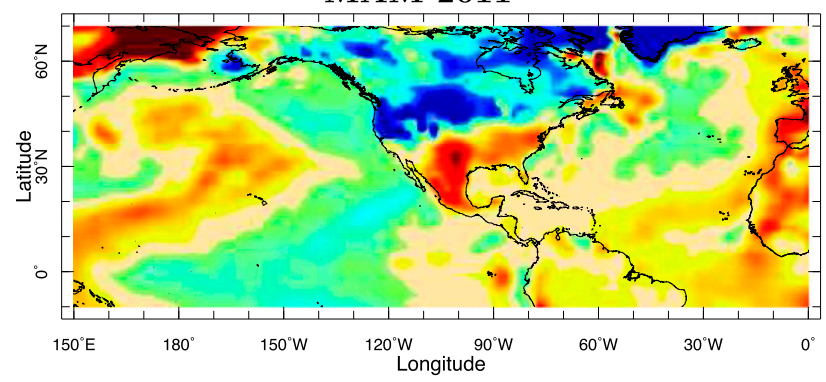

DJF 2010/2011

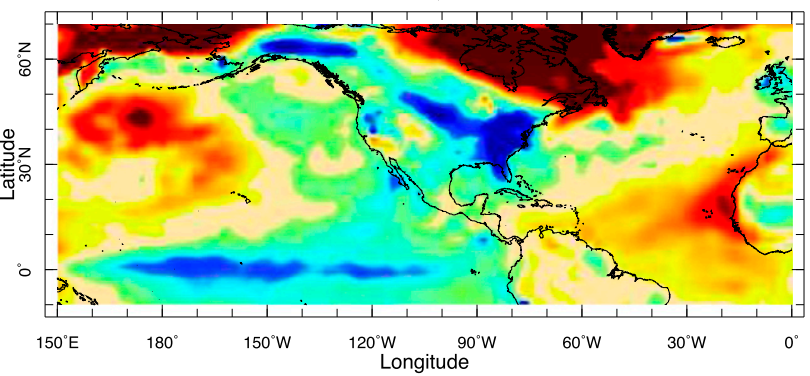

JJA 2011

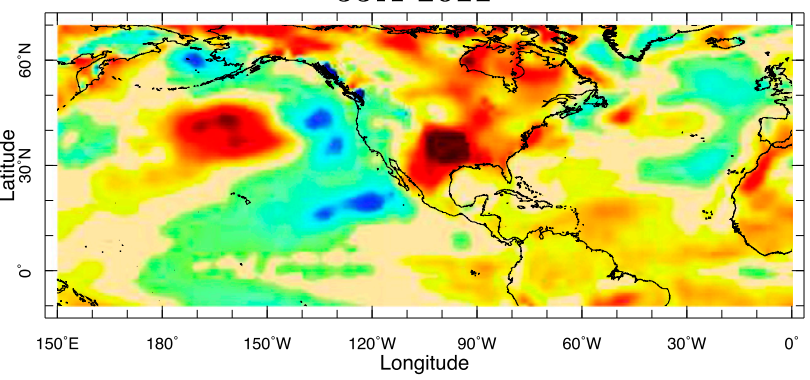

SON 2011
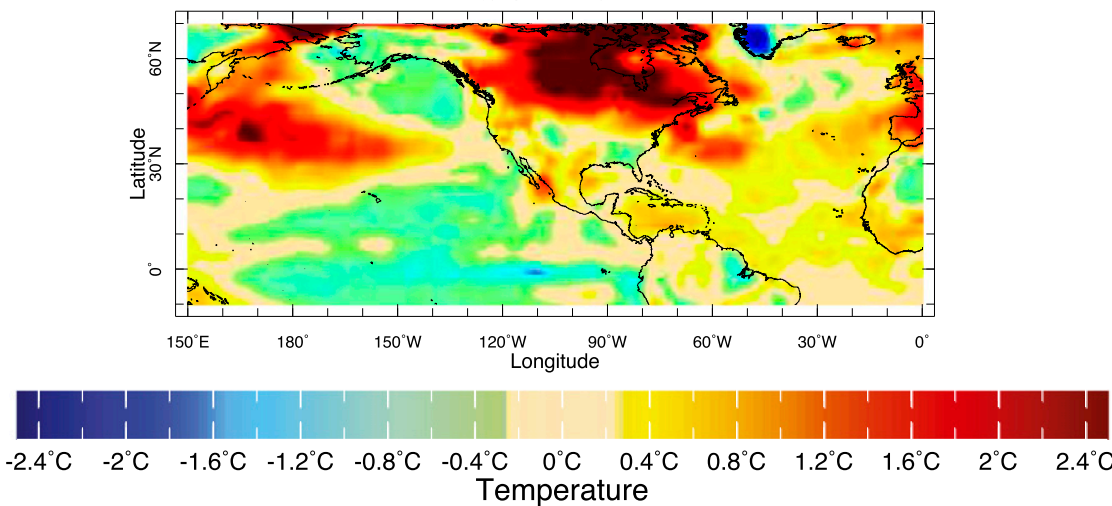

FIG. 4. The SST (over ocean) and surface air temperature (over land) during the 2010/11 TexMex drought shown in 3-month averages from SON 2010 to SON 2011.

sustained by a spatially varying mix of a reduction of evaporation and a mean flow moisture divergence anomaly. Both models agree that the transient eddy moisture convergence anomaly at this time is not very organized. The models agree that the mean flow moisture convergence anomaly moistens the Pacific coast region but provides broad areas of drying over the central and eastern United States and parts of Mexico.

In DJF 2010/11 (Fig. 7) the models agree that the negative precipitation anomaly focuses across the southern United States and all of Mexico with negative evaporation anomalies in roughly the same area. Most impressive is that the models agree that there is a strong region of anomalous transient eddy moisture divergence stretching from northern Mexico and Texas across the entire eastern United States while the mean flow produces a moisture convergence anomaly in roughly the same area but dries western Texas and the interior southwest United States. The same drying of northern Mexico, Texas, and the eastern United States by anomalous transient eddy moisture flux divergence occurs in both models in MAM 2011 while anomalous mean flow moisture divergence causes widespread drying across the central and northern Plains, Rocky Mountains, and Great Lakes region (Fig. 8).

In JJA 2011 (Fig. 9) only ECHAM4.5 has a strong negative precipitation anomaly across the United States and Mexico with a mean flow moisture divergence anomaly across much of the western United States and northwestern Mexico. But the main contributor to 


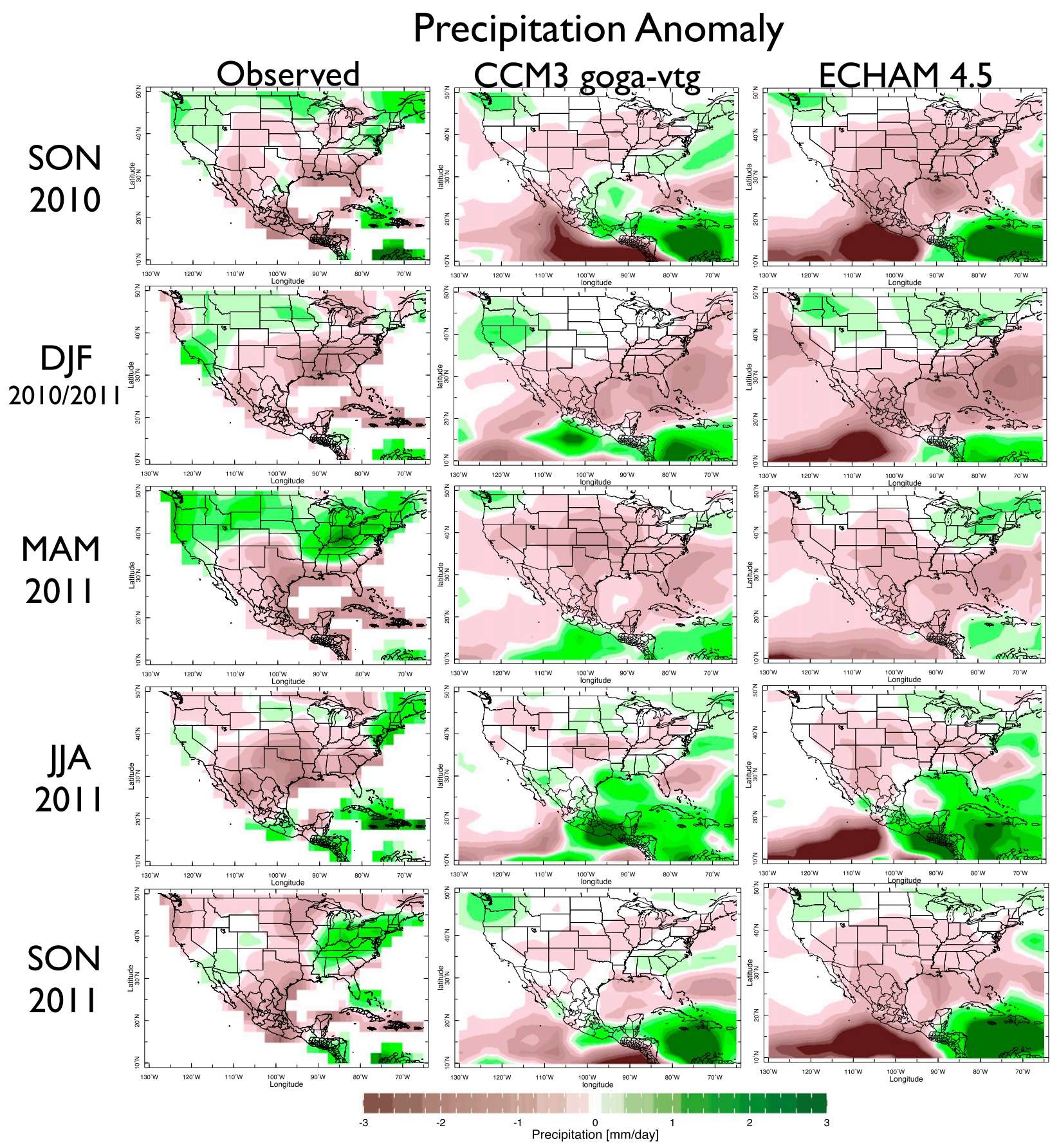

FIG. 5. Precipitation anomalies (left) observed and modeled with (middle) CCM3 and (right) ECHAM4.5: (top to bottom) seasons from SON 2010 to SON 2011, which is during the 2010/11 TexMex drought. Units are mm day ${ }^{-1}$.

widespread precipitation reduction, especially in ECHAM4.5, is the widespread negative evaporation anomalies indicative of dried soils. In SON 2011 (Fig. 10) the precipitation anomalies are amorphous in CCM3 but remain widespread and negative in ECHAM4.5 and are coincident with reduced evaporation. Both models agree on a renewed drying tendency by transient eddy moisture flux divergence in the central United States, including Texas, while ECHAM4.5 still has a mean flow moisture divergence anomaly creating a drying tendency in northern Mexico, the Southwest, and the Rocky Mountains. 
TABLE 1. Anomaly correlation coefficients accounting for area weighting between observed and modeled precipitation anomalies for the $20^{\circ}-50^{\circ} \mathrm{N}$ region, land areas only,.

\begin{tabular}{lccccr}
\hline & SON & DJF & MAM & JJA & SON \\
& 2010 & $2010 / 11$ & 2011 & 2011 & 2011 \\
\hline Obs-CCM3 & 0.05 & 0.45 & 0.33 & 0.03 & -0.30 \\
Obs-ECHAM & 0.43 & 0.41 & 0.63 & 0.32 & -0.03 \\
CCM3-ECHAM & 0.34 & 0.56 & 0.69 & 0.60 & 0.15 \\
\hline
\end{tabular}

\section{b. Moisture budget anomalies in the NCEP-NCAR and ERA-I reanalyses}

By virtue of ensemble averaging, the variations in moisture convergence or divergence in the models are caused by changes in the mean and transient atmospheric circulation that are forced by the imposed SSTs. These variations can be contrasted with those that actually occurred, as realized in reanalyses, to assess the realism of the SST-forced variations and their importance relative to variations associated with internal atmospheric variability not associated with particular ocean conditions. In Fig. 11 we show the history of variations in the convergence and divergence of vertically integrated moisture transport by the mean flow and the transient circulation as diagnosed from the NCEPNCAR reanalysis. In the first two seasons of the drought (SON 2010 and DJF 2010/11) the NCEP-NCAR reanalysis indicates that it is anomalous moisture divergence by transient eddies that contributes a drying trend across the southern United States in fall and the central United States in winter. In MAM 2011 the NCEP-NCAR moisture budget has only a transient eddy moisture divergence anomaly contributing a drying tendency over southern, mid-Atlantic, and northeastern states. In JJA and SON 2011 mean flow moisture divergence anomalies are related to extensive drying in the drought region.

The NCEP-NCAR moisture divergence anomalies bear some resemblance to the observed precipitation anomalies (Fig. 5). However, the differences are also sufficiently large that it makes sense to examine the ERA-I data as well (Fig. 12). Conveniently, the ERA-I reports the divergence of the vertically integrated moisture transport as a diagnostic quantity. This is plotted along with the mean and transient flow components as computed by us. With the partial exception of MAM and JJA 2011, the actual ERA-I moisture divergence or convergence anomaly quite closely matches the observed precipitation anomaly. Since the sum of the two components quite closely matches the actual divergence or convergence (not shown), the partition can be considered valid and useful.

Comparing Figs. 11 and 12, it is seen that there is notable agreement between the two reanalyses in the patterns of moisture divergence and convergence by the mean and transient flow. In SON 2011, ERA-I suggests a mean flow drying of Texas and the Plains and both it and NCEP-NCAR indicate transient flow drying of much of southern North America. In DJF 2011 ERA-I also suggests a mean flow moisture divergence anomaly drying Texas, northeast Mexico, and the Southeast, adding to a more general transient component drying that again agrees with NCEP-NCAR. In MAM 2011 ERA-I agrees with NCEP-NCAR on a transient component drying from northeast Mexico to the Northeast that is opposed by a mean flow moistening. In JJA 2011, at the height of the 2010/11 drought, ERA-I indicates that anomalous mean flow moisture divergence was widespread across North America, largely confirming the results from NCEPNCAR. Widespread, but weaker, mean flow moisture convergence anomalies persisted into SON 2011, again confirming the NCEP-NCAR results.

In summary, both reanalyses suggest that the drought was associated with a combination of mean and transient flow moisture divergence anomalies in fall 2010 and winter 2010/11 but that by spring, summer, and fall 2011 the mean flow divergence anomalies were dominant. The next step is to relate these anomalies in the moisture budget to the anomalies in the mean and transient atmospheric circulation that are the ultimate cause of the drought.

\section{Causes of the 2010/11 TexMex drought}

\section{a. Mean atmospheric circulation anomalies}

In relating the moisture convergence and divergence anomalies to circulation anomalies we make use of the simple concept that increased moisture convergence and precipitation are associated with rising motion and vice versa, as shown for El Niño and La Niña in prior work (Seager et al. 2005a). Then we expect, on large scales, rising motion anomalies to be found where the mean flow is poleward, and descending motion where the mean flow is equatorward, according to a simple vorticity balance between advection of planetary vorticity and vortex stretching and thermal balance between meridional advection and adiabatic cooling or warming due to vertical motion and expansion or compression. Of course, the vorticity and thermal budgets controlling the location of vertical motion anomalies are in reality more complex than this, but this reasoning will be applied below to guide the linking of circulation and moisture budget anomalies.

In Fig. 13 we show the reanalysis $200-\mathrm{mb}$ height anomalies by season from SON 2010 through SON 2011 together with the ensemble mean of the CCM3 and 


\section{CCM3}
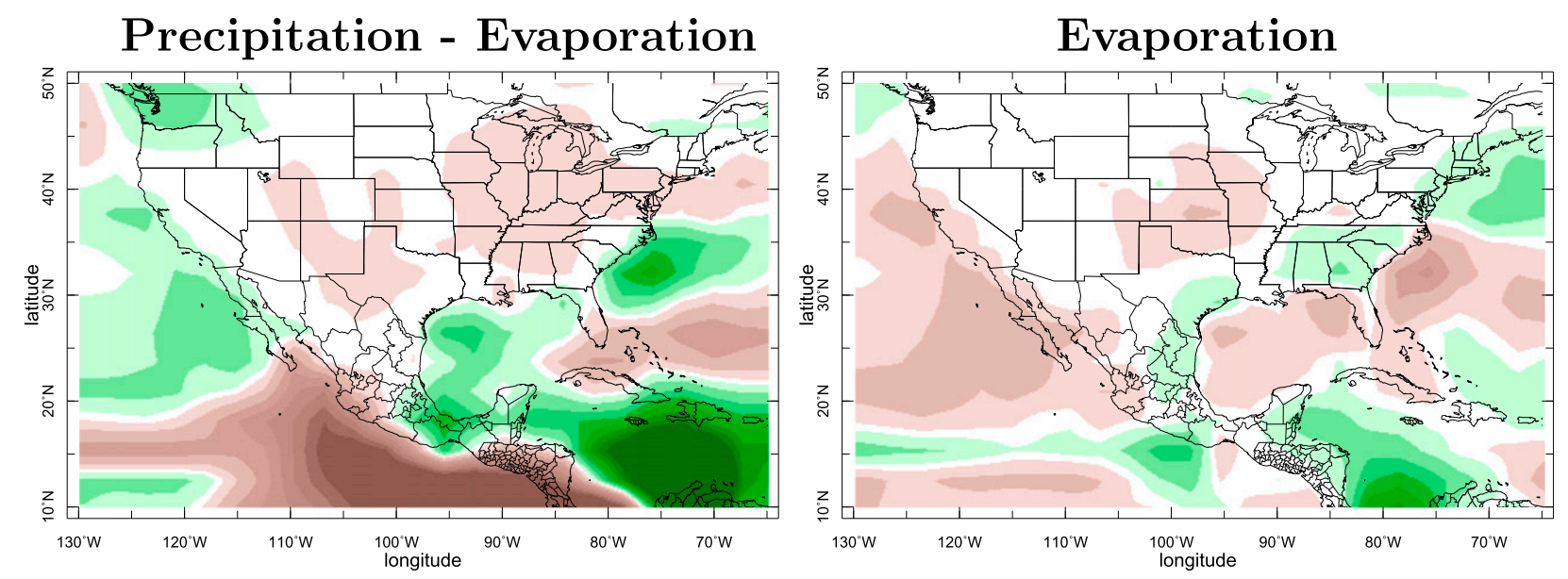

Moisture Convergence
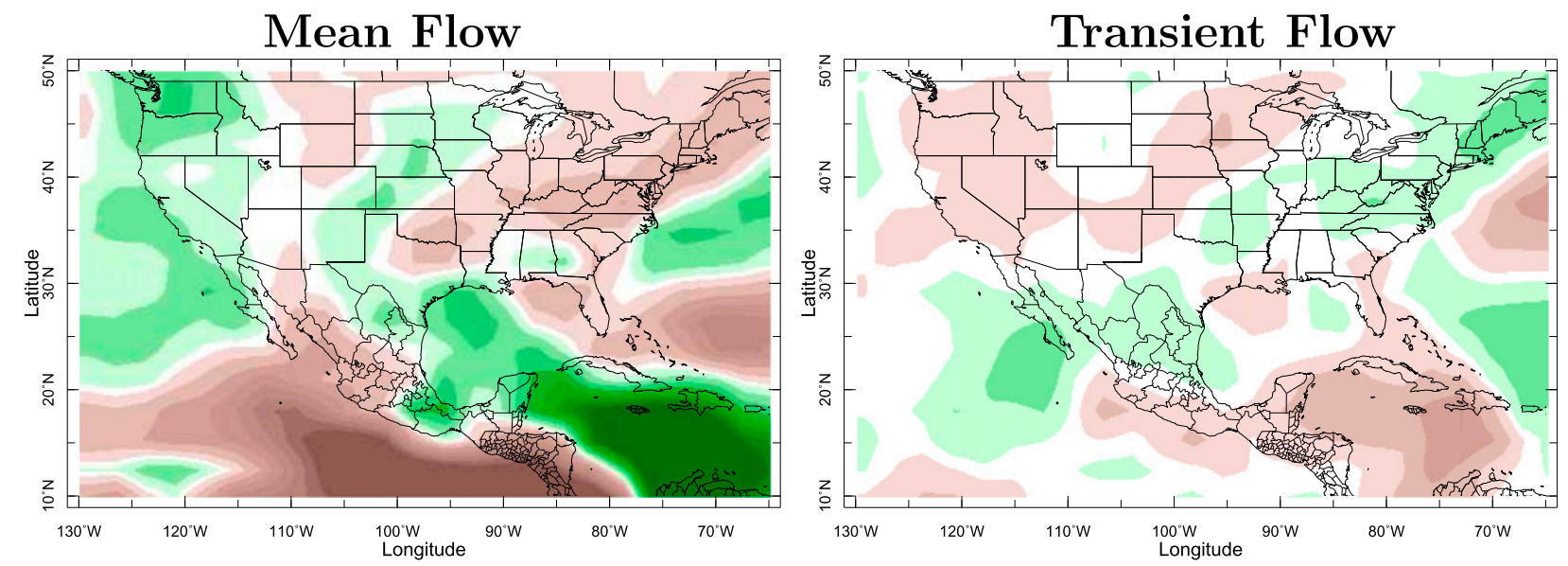

FIG. 6. The modeled moisture budget anomalies for the CCM3 and ECHAM4.5 models. Each set of four panels shows the model anomalies in precipitation, evaporation, vertically integrated mean flow moisture convergence, and the vertically integrated transient eddy moisture convergence. Results are for fall (SON) of 2010. Units are mm day ${ }^{-1}$.

ECHAM4.5 simulations. Throughout the entire period, but weakest in JJA 2011 when the tropical SST anomalies were weakest, the observations and models show low tropical heights and off-equatorial cyclones over the Pacific consistent with forcing from cold La Niña SST anomalies. In SON 2010 the observations show a midlatitude pattern that is quite similar to the typical fall $\mathrm{La}$ Niña height anomaly pattern (Fig. 5) and that includes a low over the Pacific Northwest and a high over the central North America. Reasoning on the basis of the associated mean flow and moisture divergence anomalies, this is consistent with increased precipitation in the northwest United States and western Canada and dry anomalies farther south as observed (Figs. 5, 11, and 12). The models both have extratropical height anomaly patterns typical of La Niña (Figs. 1-3) with widespread subtropical to midlatitude ridges (e.g., Straus and Shukla 2002; Seager et al. 2003). This provides evidence that the observed subtropical to midlatitude highs over Asia, the North Pacific, and North America were largely a forced response to the emerging 2010/11 La Niña. The observed low anomaly west of Canada is typical of La Niña in SON but the models are not capable of simulating this feature faithfully (as seen in Figs. 1-3).

In DJF 2010/11 the reanalysis shows a typical La Niña pattern (Fig. 1) over a strong high over the North Pacific. No similarity is seen over eastern North America and the Atlantic where a strong negative North Atlantic Oscillation (NAO) event developed. ECHAM4.5 also develops a strong high over the North Pacific while, oddly, the CCM3 does not. The models, not surprisingly, fail to produce the negative NAO event. The observed 


\section{ECHAM 4.5}
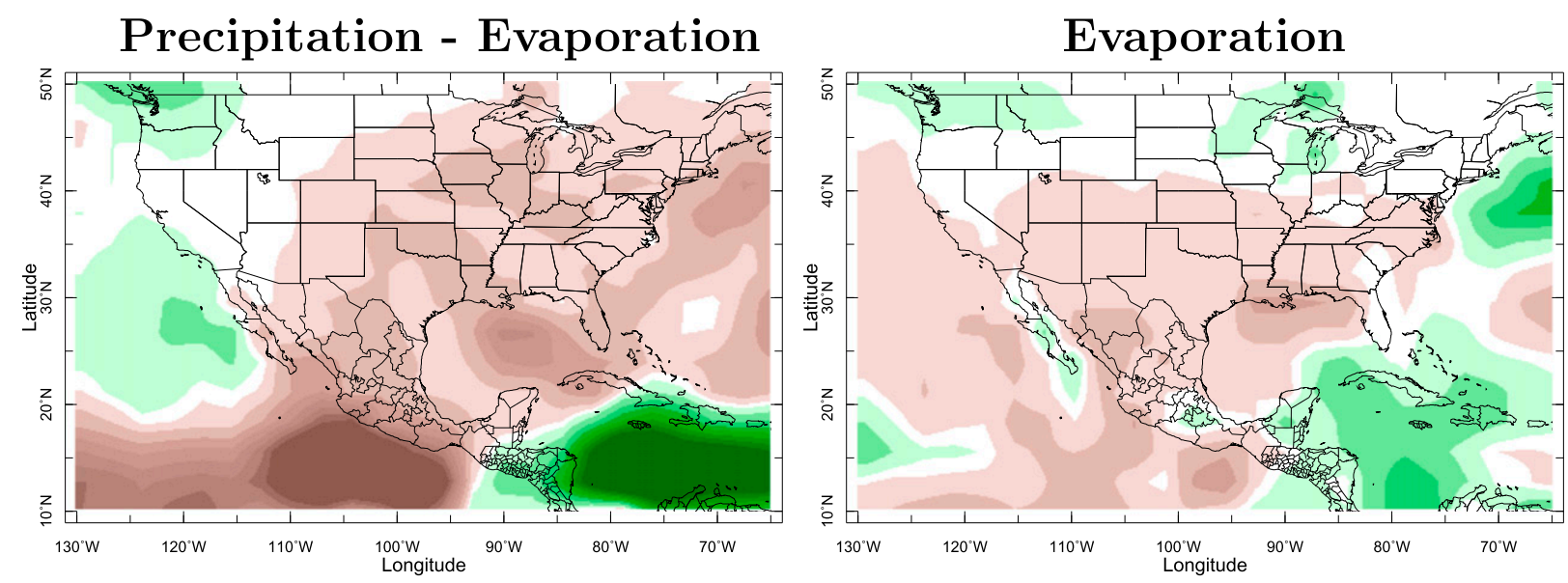

Moisture Convergence
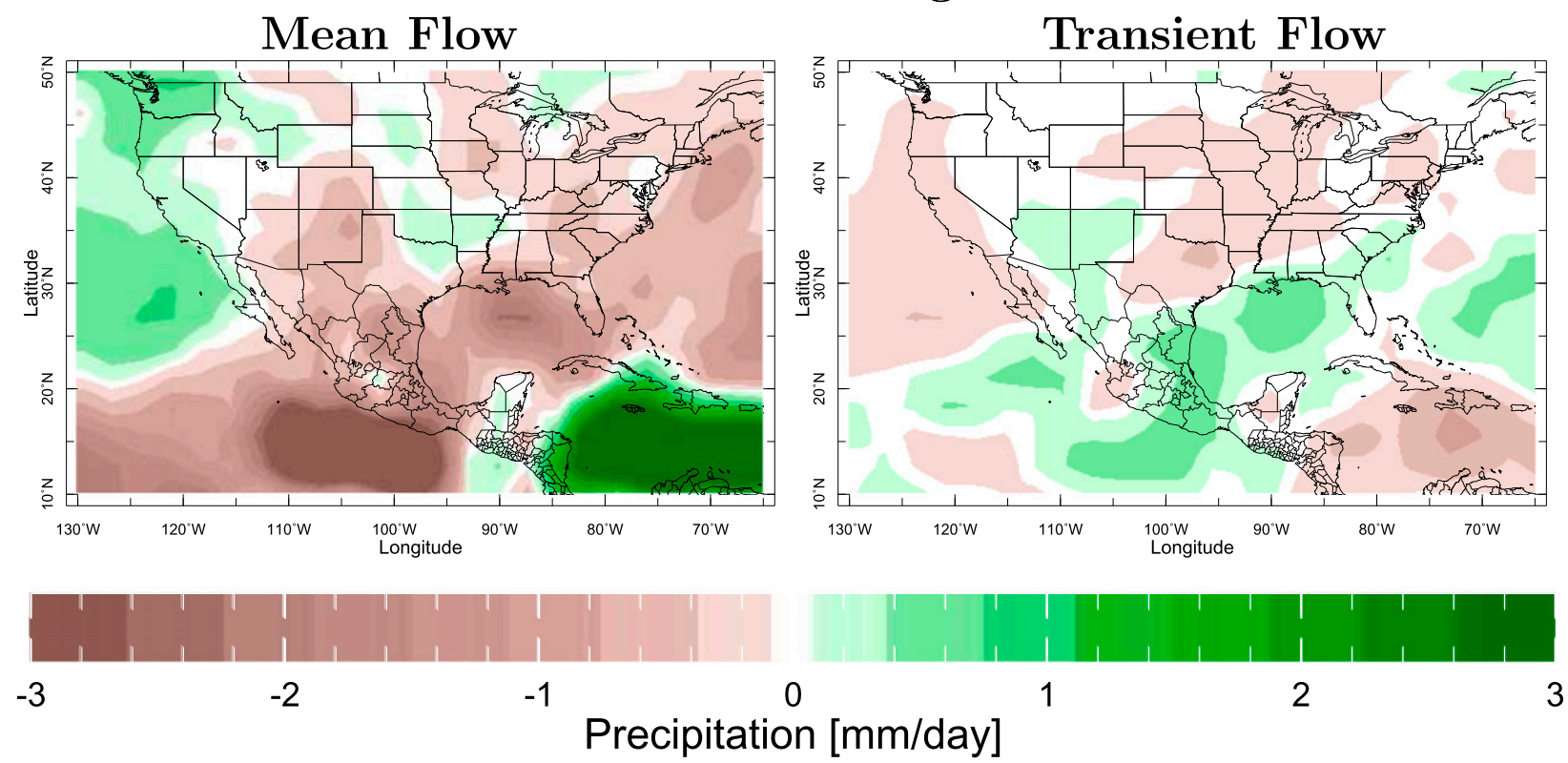

FIG. 6. (Continued)

height anomalies, including the strong northerly flow over the central and eastern United States associated with the negative NAO, are consistent, via mean flow moisture divergence, with negative precipitation anomalies in the southwest United States and across the central and eastern southern United States as observed (Figs. 5, 8, and 9). In contrast, the ECHAM4.5 height anomalies are consistent with reduced precipitation over the west coast of North America due to anomalous mean flow moisture divergence (Fig. 7). The modeled high off the U.S. Southeast is consistent with modeled anomalous mean flow moisture convergence over the eastern United States (Fig. 7), which is distinct from the observed NAOinduced drying in the region.
In MAM 2011 the models retain the character of a La Niña-forced height anomaly pattern consistent with the continued, but weakening, cool tropical Pacific SSTs. The reanalysis observations also have some similarity to the observed MAM La Niña composite (Fig. 1) with a zonally oriented band of high pressure in the AsiaPacific-North American sector sandwiched between low anomalies in the tropics and high latitudes. However, the limited similarity to the typical La Niña pattern indicates a substantial component of internal atmospheric variability in the MAM 2011 pattern. The observed height anomalies drive westerly anomalies into the Pacific Northwest that are consistent with, via a mean flow moisture convergence anomaly, a wet Pacific 


\section{CCM3}

\section{Precipitation - Evaporation}

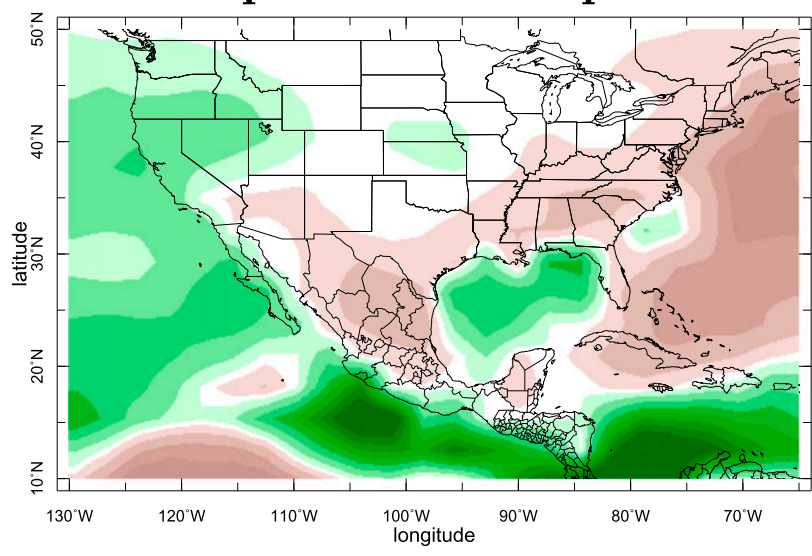

Evaporation

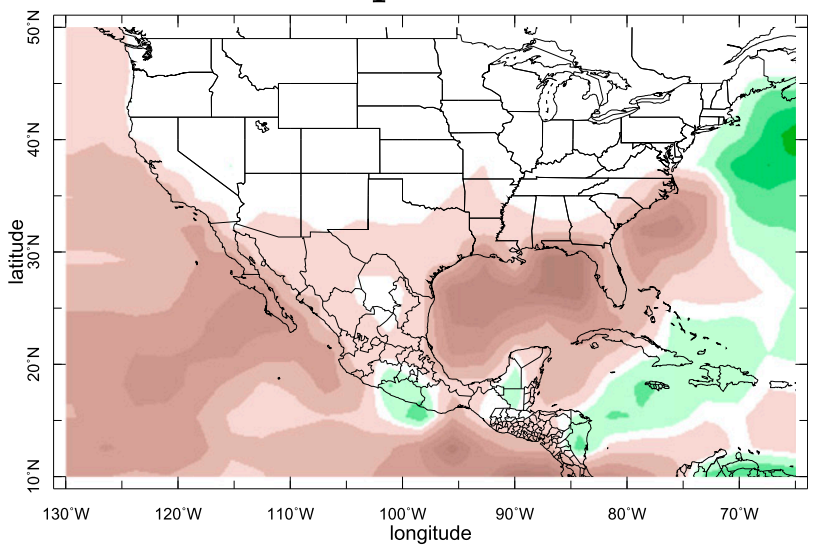

Moisture Convergence
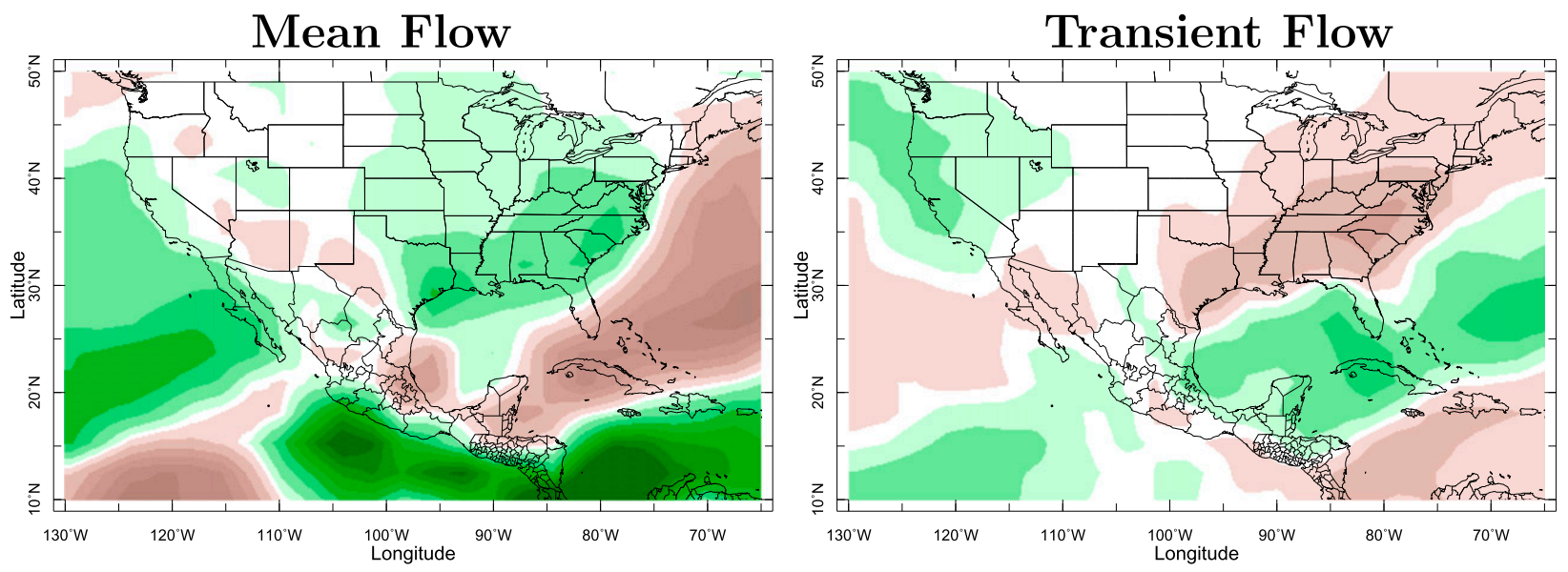

FIG. 7. As in Fig. 6, but for DJF 2010/11.

Northwest as observed (Figs. 5 and 8). The model precipitation anomalies, with dry anomalies extending farther north than observed (Fig. 5) and caused by a combination of mean flow moisture divergence (to the north) and transient eddy moisture divergence (to the south) (Fig. 8), are different from observations but consistent with their more canonical La Niña height anomalies.

In JJA 2011, as the La Niña continued to wane, the models provide no evidence of a strong extratropical circulation response. The reanalysis observations, however, show a localized upper-level high anomaly over the North American continent consistent with the negative precipitation anomalies (see Ting and Wang 1997) but unlike the very weak observed composite JJA La Niña pattern (Fig. 1). The observed JJA high anomaly is weak, which, as further investigation reveals, results from averaging over three quite different anomalies, with July 2011 having the strongest high. This month-to-month variation supports the suggestion that the JJA 2011 dry anomaly was a result of internal atmospheric variability. In SON 2011, the La Niña regained strength and the models responded with canonical height anomalies. The observed height anomaly appears dominated by internal atmospheric variability and has a high over northeast Canada and a low over the southern United States. This favored dry conditions over much of the southern United States and wet conditions over the northeast United States via mean flow moisture divergence-convergence anomalies (Figs. 5, 11, and 12). The models notably fail to simulate that precipitation pattern, suggesting that it may not be forced by SSTs.

In summary, the evolution of the height anomalies in the observations and SST-forced models suggest that the 2010/11 La Niña played an important role in causing the development of the TexMex drought from fall 2010 to spring 2011 but that even within that season, and entirely 


\section{ECHAM 4.5}
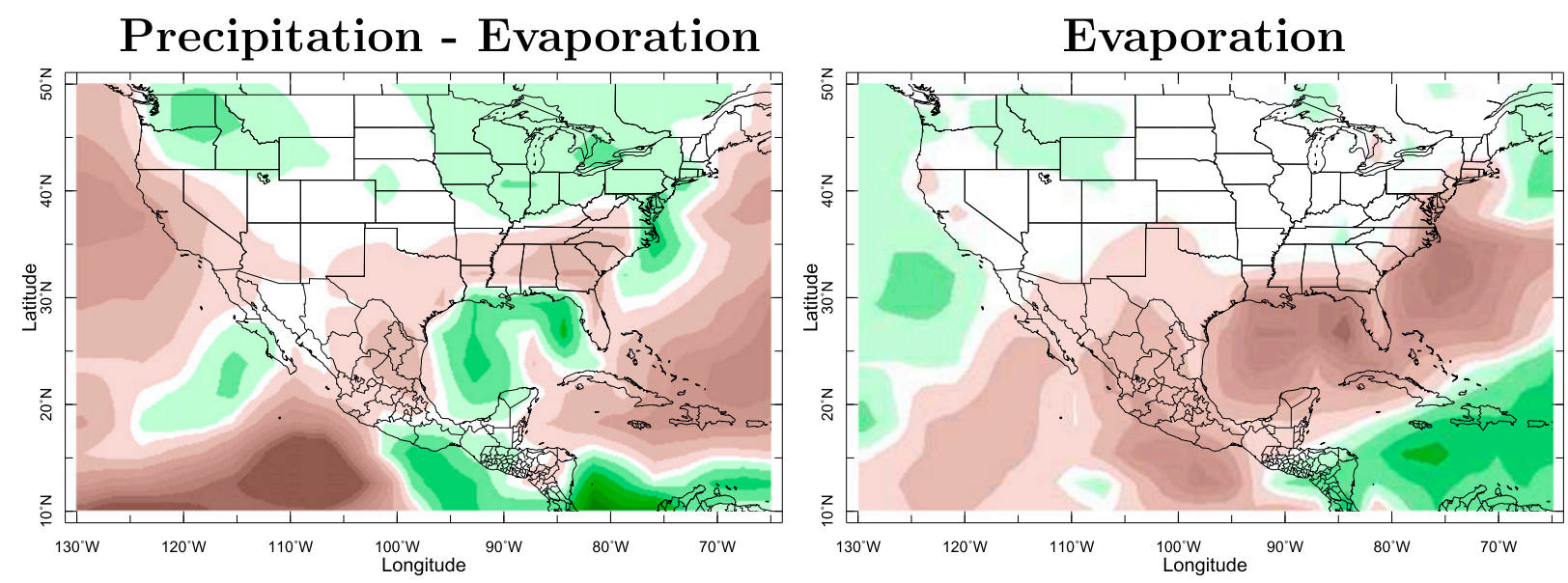

\section{Moisture Convergence}
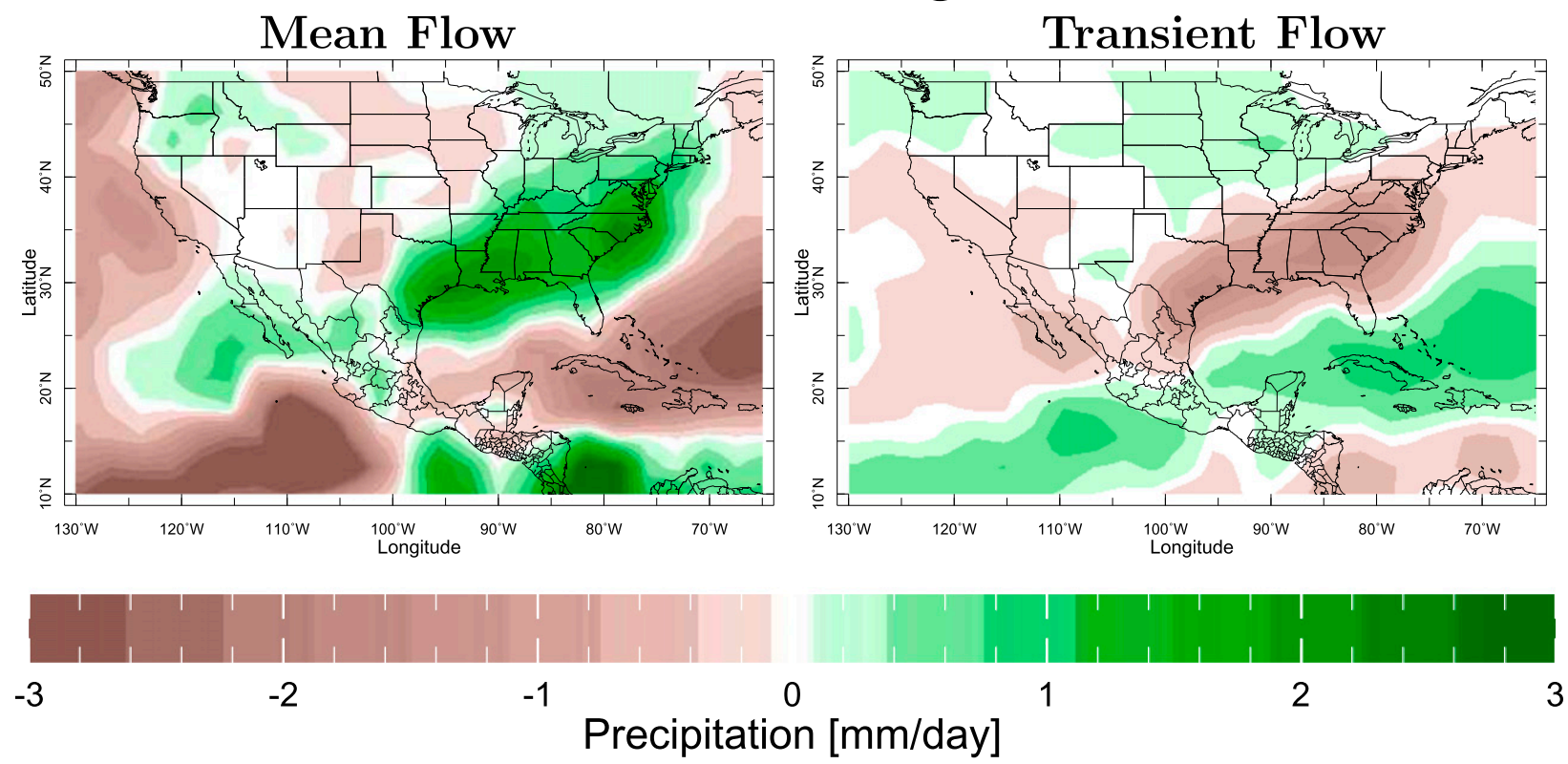

FIG. 7. (Continued)

for summer and fall of 2011, internal atmospheric variability unrelated to ocean conditions played a critical role in determining the severity and persistence of the drought.

\section{b. Transient atmospheric circulation anomalies}

The previous section drew connections between changes in mean flow and the precipitation anomalies of the 2010/11 TexMex drought. Now we examine the changes in the reanalysis observed and modeled transient eddy fields to attempt to understand the contribution of changes in eddy moisture convergence. As shown in Fig. 14, in SON 2010, amidst considerable differences, the reanalysis observations and models suggest a poleward shift in the pattern of upper tropospheric eddy meridional velocity variance, $\overline{v^{\prime 2}}$, that extends across central North America as is typical of La Niña events (see Seager et al. 2010a). This would be expected to contribute a transient eddy drying tendency to most of the United States in rough agreement with the computed model transient eddy moisture flux convergence anomalies in Fig. 6 and the reanalysis ones in Figs. 11 and 12.

In DJF 2010/11 the reanalysis observations and models agree on increases in $\overline{v^{\prime 2}}$ over the North Pacific north of $30^{\circ}-40^{\circ} \mathrm{N}$ and over the Pacific coast of North America. There is little agreement between models and 


\section{CCM3}

\section{Precipitation - Evaporation}

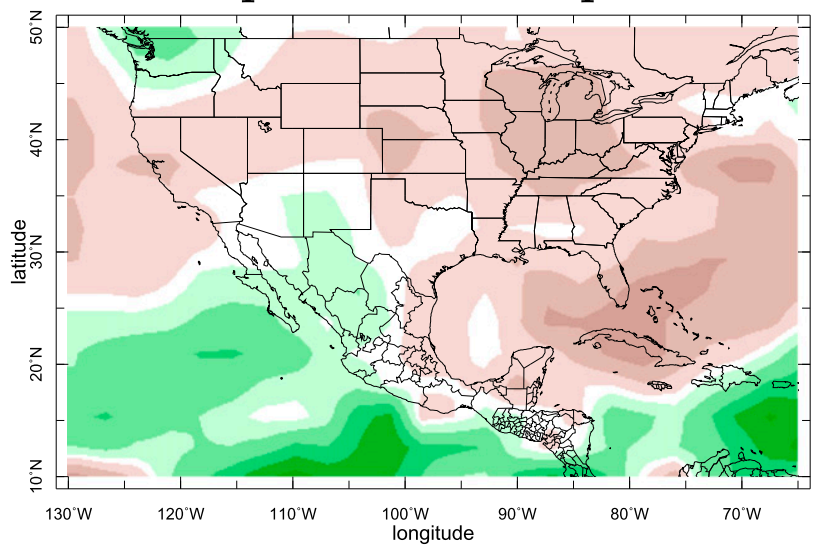

Evaporation

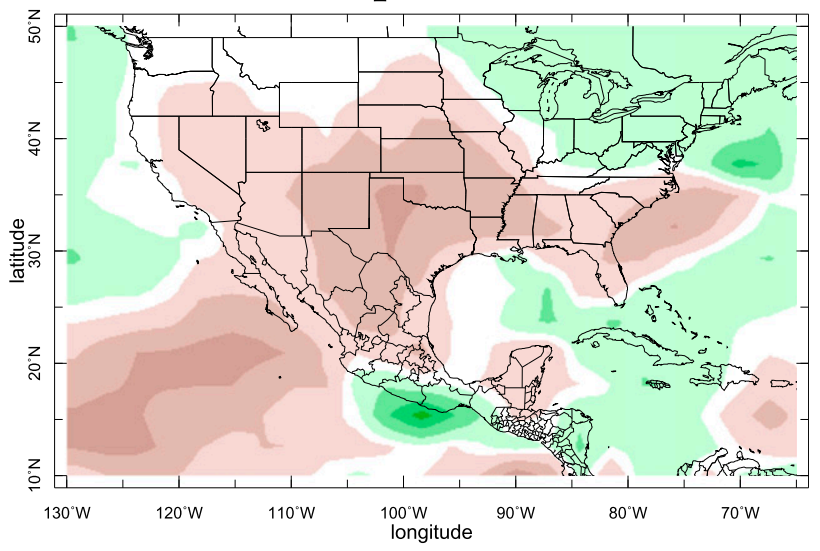

Moisture Convergence
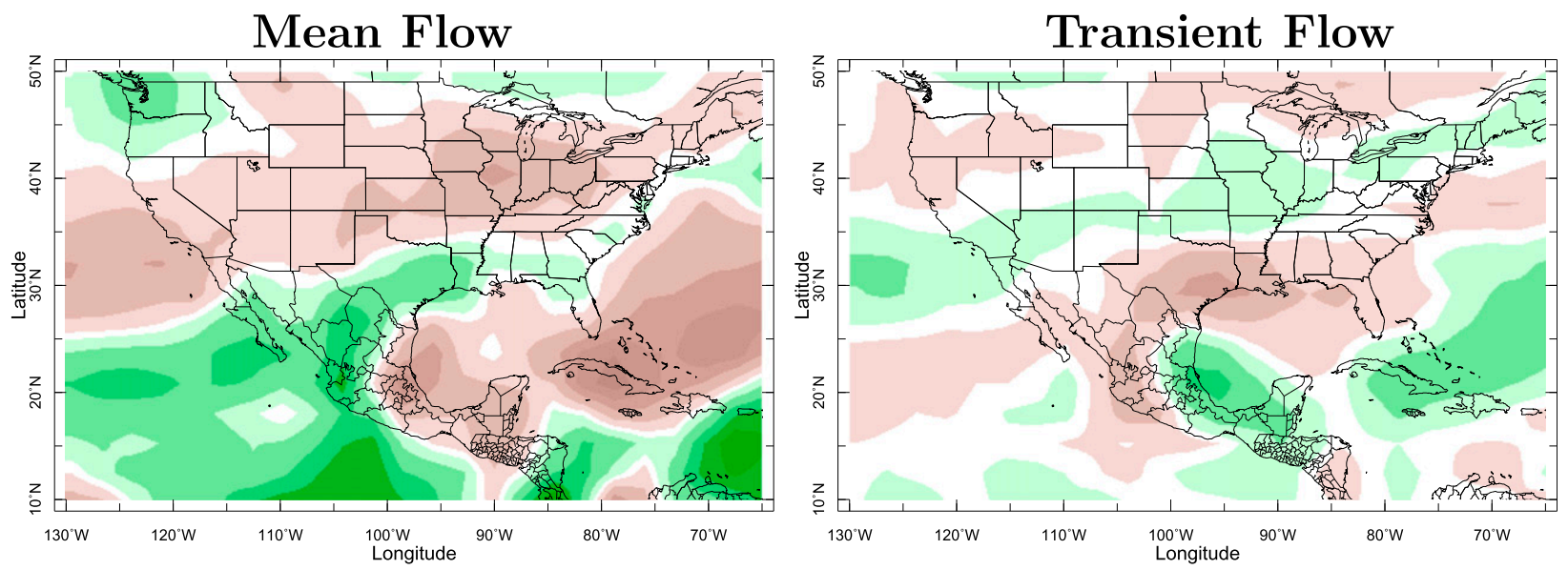

FIG. 8. As in Fig. 6, but for MAM 2011.

observations farther east over North America. In the models the transient eddy anomalies are consistent with a transient eddy moisture divergence anomaly over the south and southeastern United States translating into a drying tendency as seen in Fig. 7. The disagreement with the observed $\overline{v^{\prime 2}}$ anomalies suggests that the actual $P$ reduction in this region was not sustained in this way and it could instead have been caused by mean flow moisture divergence associated with the negative NAO event (Fig. 13).

In MAM 2012 the models again agree on strengthening of $\overline{v^{\prime 2}}$ across the North Pacific and North America on the poleward flanks of the upper tropospheric high anomalies seen in Fig. 13. The reanalysis observations have some similarity to the models with increased $\overline{v^{\prime 2}}$ over central North America but with the addition of a strong and widespread reduction over Canada. The observed and modeled patterns are consistent with anomalous transient eddy moisture divergence and drying over south central and southeast North America. The transient eddy anomalies are weak in JJA 2011. In SON 2011, the observations have increased $\overline{v^{\prime 2}}$ over North America. Only CCM3 of the two models is roughly consistent with the SON $2011 \overline{v^{\prime 2}}$ pattern and has transient eddy drying over the southern United States (Fig. 10) although the reanalyses do not support this (Figs. 11 and 12). ECHAM 4.5 has a pattern of $\overline{v^{\prime 2}}$ over the North Pacific and west coast of North America that is similar to that of CCM3 but the patterns are quite different over central and eastern North America.

In summary, the reanalyses provide some evidence for a role of transient eddy moisture transports in generating the drought (especially transient eddy drying over the southern United States in MAM 2011), the evidence for SST forcing of these anomalies is limited. This probably reflects the mix in observations, for the single seasons, of 


\section{ECHAM 4.5}
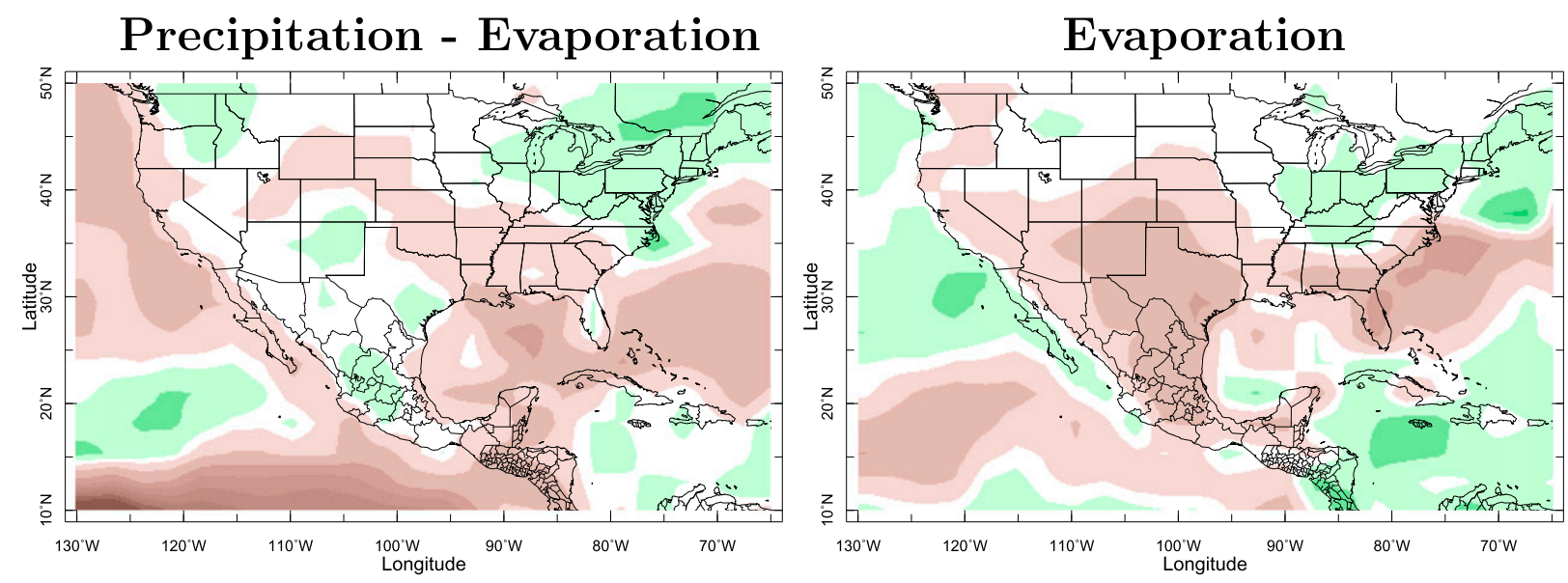

Moisture Convergence
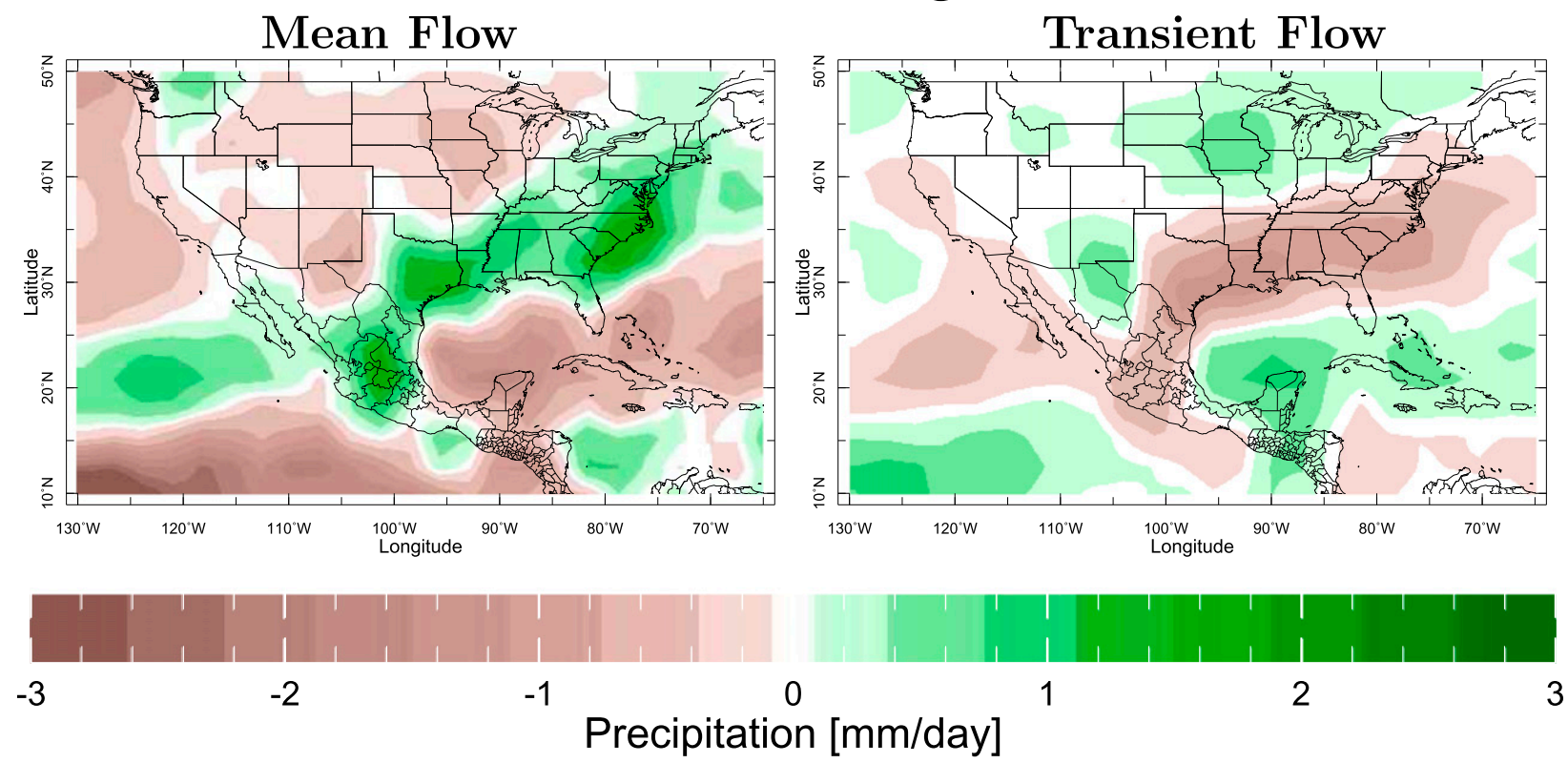

FIG. 8. (Continued)

a modest SST-forced component with a much larger component of internal atmospheric variability.

\section{How unusual was summer 2011 of the TexMex drought?}

Droughts and heat waves are recurring features of the climate of Texas and Mexico so the question arises as to whether the 2010/11 event was in any way unusual. In the summer of 2011 many high temperature records were broken across the region so we focus on the JuneAugust season. Figure 15 shows a scatterplot of observed and modeled JJA surface air temperature and precipitation anomalies for the 1950-2011 period averaged over land areas between $22^{\circ}$ and $40^{\circ} \mathrm{N}$ and $105^{\circ}$ and $90^{\circ} \mathrm{W}$. The observations show that dry summers go along with high temperatures as noted before (e.g., Madden and Williams 1978; Mueller and Seneviratne 2012). This is a simple result determined by a mix of 1) reduced moisture availability at the surface necessitating that incoming solar radiation be balanced less by evapotranspiration and more by sensible heat flux and longwave radiative cooling, requiring higher surface temperatures, and 2) reduced cloud cover increasing surface downward solar radiation. JJA 2011 stands out as both the driest and hottest JJA since 1950 in this region but does not appear 


\section{CCM3}

\section{Precipitation - Evaporation}

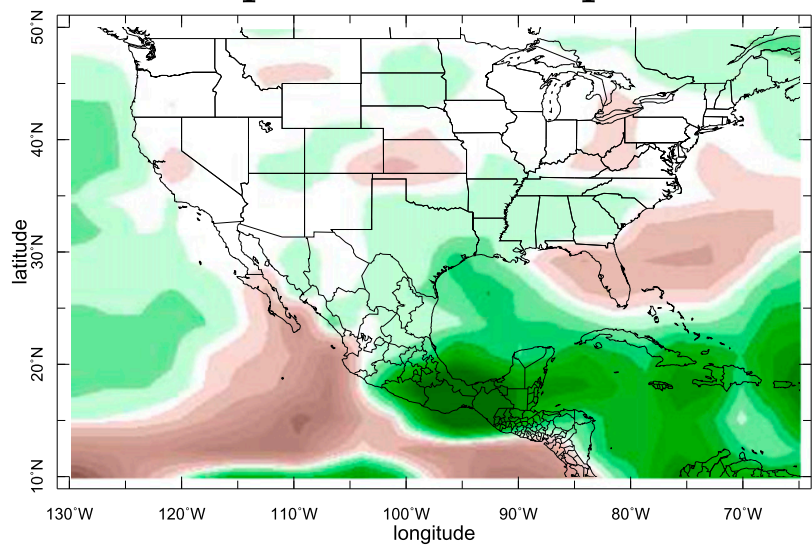

Evaporation

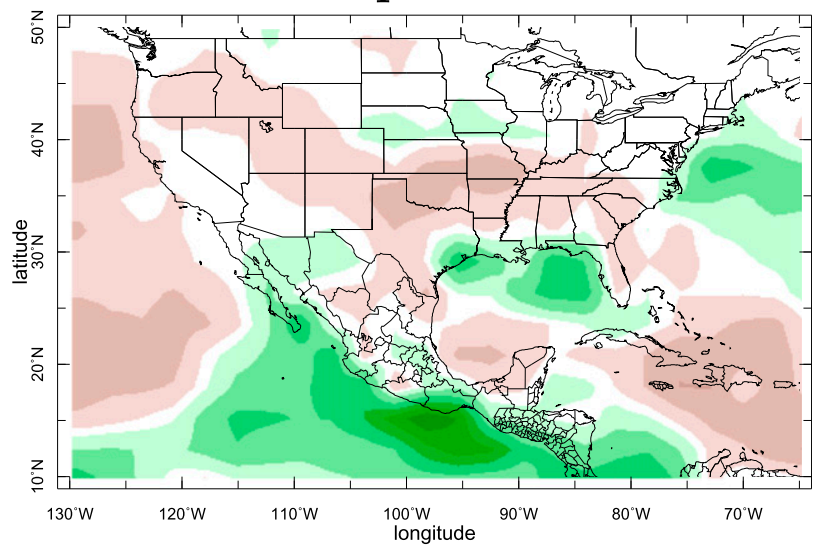

Moisture Convergence
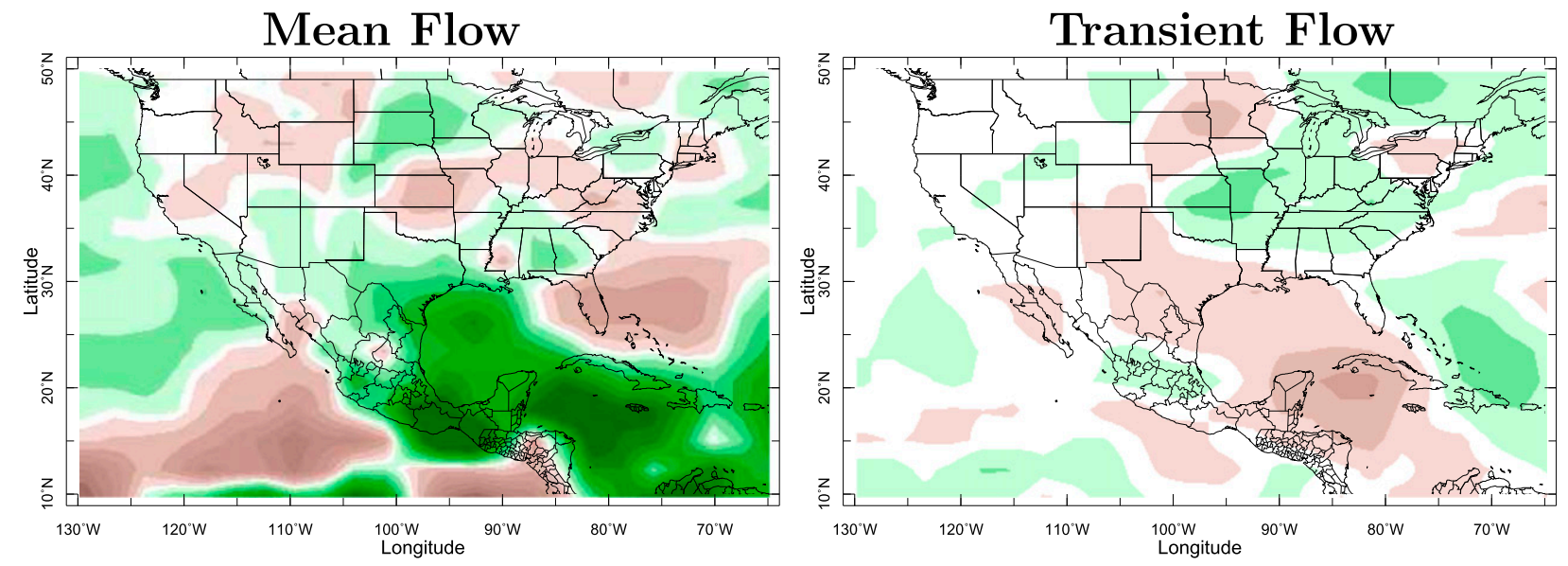

FIG. 9. As in Fig. 6, but for JJA 2011.

as an outlier in that, given the precipitation reduction, the temperature is what would be expected and it is accompanied by a close analog (JJA 1980).

The values plotted for the two models are from the individual ensemble members and hence, like the observations, contain the effects of both SST forcing and internal atmospheric variability. The models produce an inverse relation between temperature and precipitation variability comparable to that observed (arising from increased solar radiation receipt and a shift to cooling by sensible and longwave loss in dry years; not shown). The individual ensemble member simulations of JJA 2011 are plotted as green crosses and are clearly biased warm for the associated precipitation anomaly. Note that the circles in Fig. 15 are color coded according to year and that for the models the later years are typically warmer than the earlier years. This, and the 2011 values, indicates the effect of global warming, which is included in both models via the imposed SST history and additionally in $\mathrm{CCM} 3$ via imposed changes in $\mathrm{CO}_{2}$ and $\mathrm{CH}_{4}$. No warming tendency appears in the observations where precipitation is instead the dominant control on JJA temperature. The JJA 2011 precipitation anomalies in CCM3 were scattered around zero (see Fig. 5) but were biased dry for ECHAM4.5. Two ensemble members (one from each model) achieved a JJA 2011 drying and warming that essentially matches that observed. In a similar analysis for Texas alone (which is a subset of our larger domain) Hoerling et al. (2013) found that 2011 was a true outlier and concluded that background global warming likely was responsible for the warming above what would be expected given the precipitation reduction. This is not so striking for the larger region considered here. The observations suggest the JJA 2011 drying and warming was a once or twice a century event but the much larger sample size of the models, if they 


\section{ECHAM 4.5}
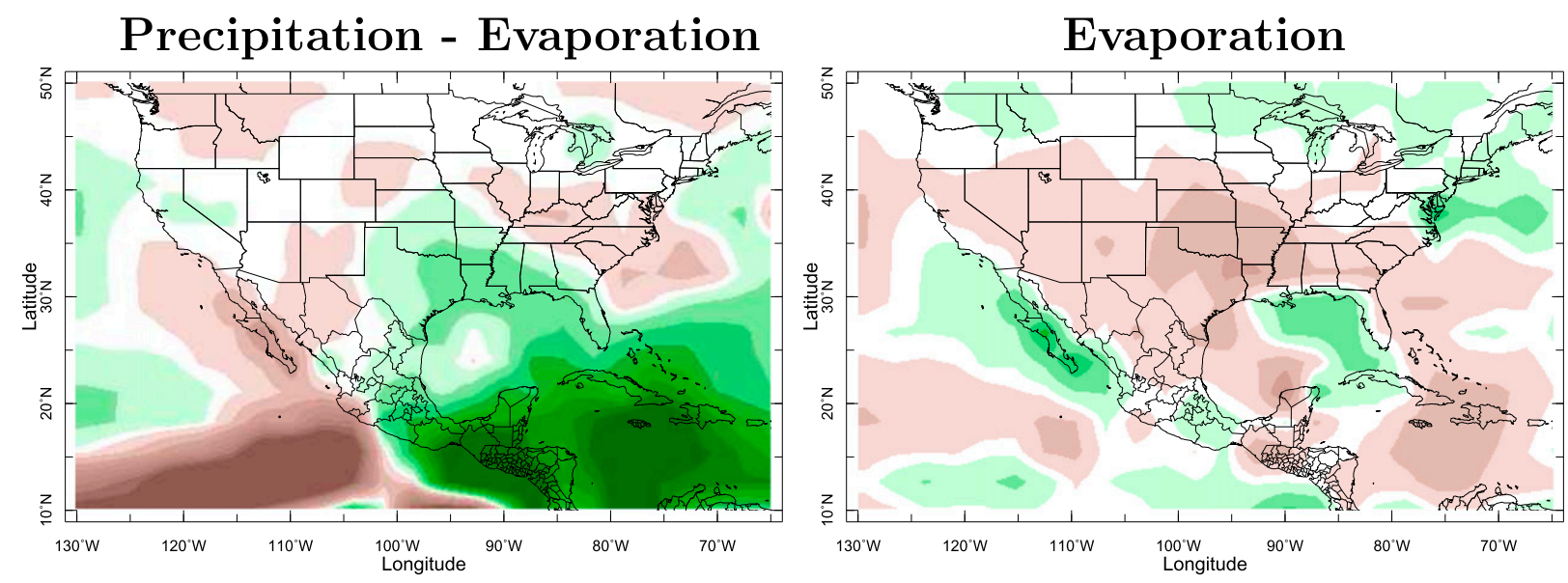

Moisture Convergence
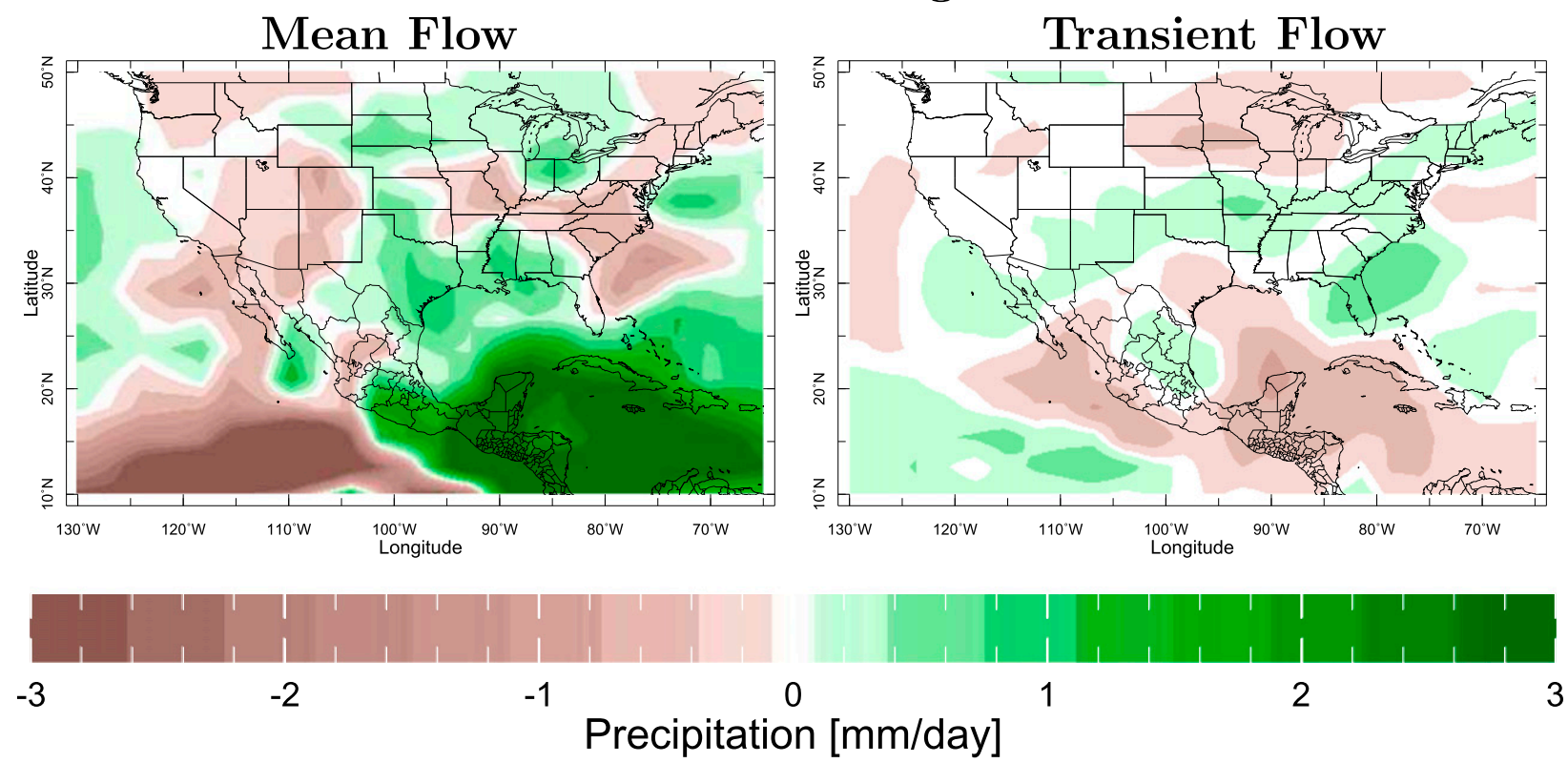

FIG. 9. (Continued)

can be trusted at face value, indicate an even lower likelihood.

Another way of looking at the observed precipitation and temperature history is seen in Fig. 16, which shows the time history of JJA average observed temperature (on an inverted scale) and precipitation for 1950 to 2011 averaged over the TexMex region. The inverse relation between the two quantities is also abundantly clear here, with 2011 standing out as having the driest JJA and, hence, the warmest one too. The hot and dry summer of 1980 is also clear. The string of hot dry summers in the 1950s and the cooler and wetter extended period from the mid-1960s through the mid-1990s also stand out. Amidst this variability, neither temperature nor precipitation in the TexMex region has a clear trend. The expected greenhouse gas-driven trend to drier conditions in the TexMex region (Seager et al. 2007; Seager and Vecchi 2010) is quite likely currently masked by the presence of large-amplitude natural variability on interannual to multidecadal time scales (Hoerling et al. 2013).

\section{How well was the $\mathbf{2 0 1 0 / 1 1}$ drought forecast by operational seasonal-to-interannual prediction systems?}

Understanding the dynamical causes of droughts is important but more important from the point of view of planning ahead for, and possibly preventing, damaging 


\section{CCM3}

\section{Precipitation - Evaporation}

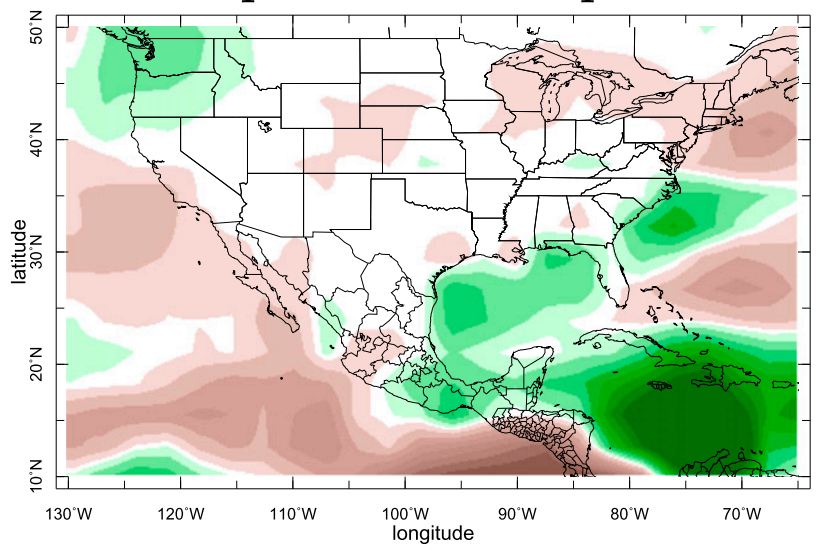

Evaporation

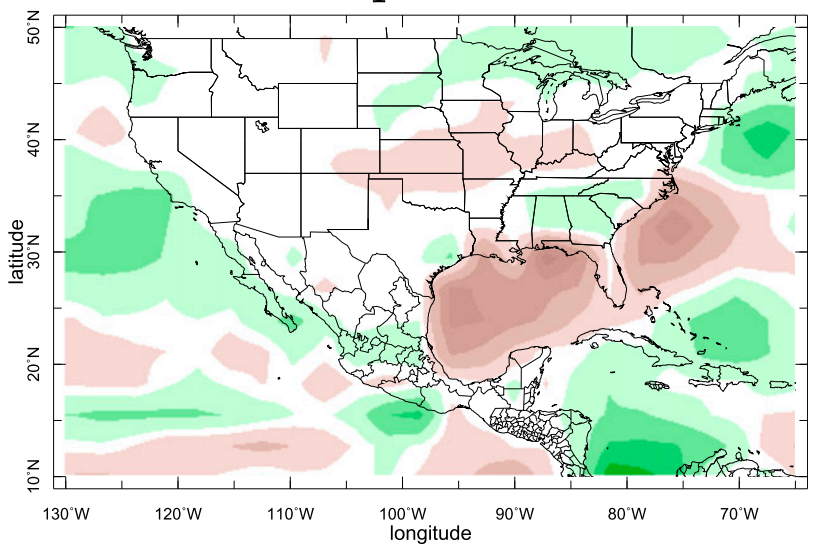

\section{Moisture Convergence}
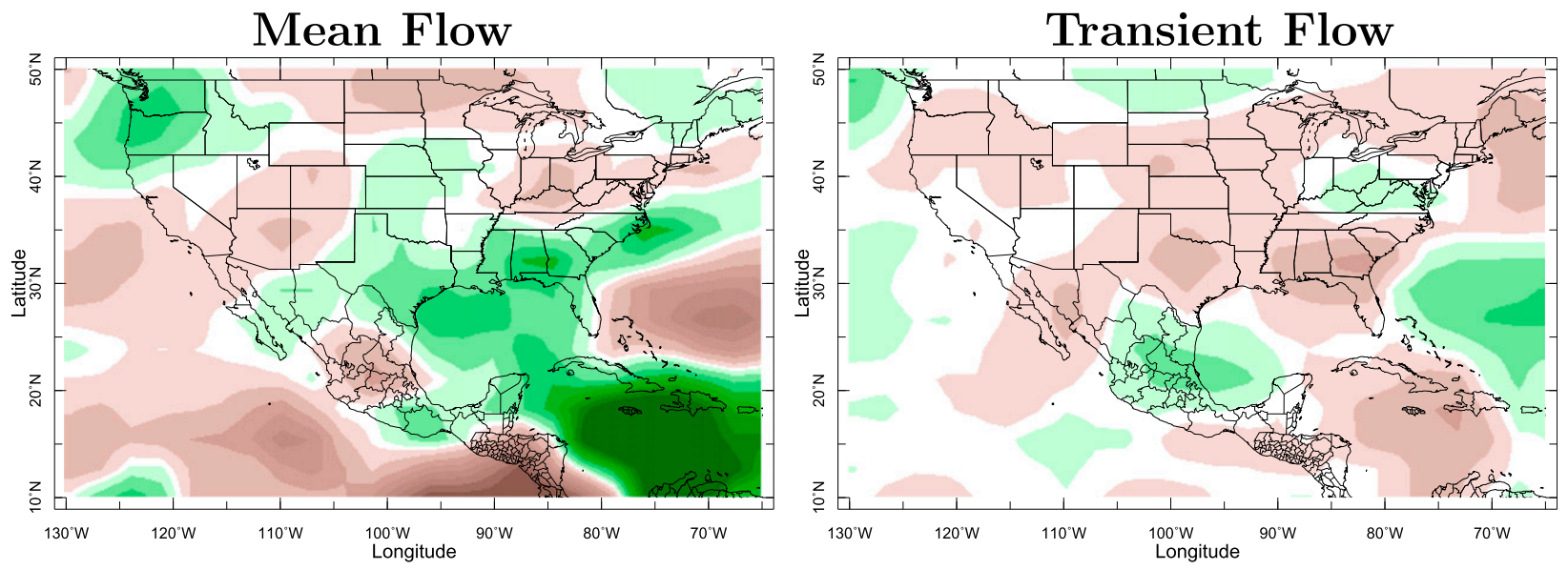

FIG. 10. As in Fig. 6, but for SON 2011.

impacts is development of an ability to predict droughts. Prediction of drought on the seasonal-to-interannual time scale will depend on the ability to predict slowly evolving boundary conditions that, by forcing the atmospheric circulation, can create tendencies toward drought-inducing patterns of sufficient amplitude that they can emerge amidst the internal atmospheric variability. SSTs and soil moisture anomalies are the boundary conditions to be predicted, with the former being the one that has been best shown to provide predictability. Our analysis has shown that we would expect some skill in prediction of the onset and development of the drought in fall and winter 2010/11 but that forecasts would have little skill in summer 2011 when internal atmospheric variability played an important role.

The International Research Institute for Climate and Society (IRI) produces each month seasonal forecasts of precipitation based on predictions of the evolving ocean state and the atmospheric response to it. The real-time forecasts issued by the IRI (i.e., the Net Assessments) over the United States are taken from the operational forecasts from the Climate Prediction Center (CPC) of the National Weather Service in which the multimodel ensemble product from the IRI (Barnston et al. 2010) ${ }^{2}$ is one input. Here we just present the IRI multimodel ensemble results for the global SST and North American precipitation forecasts but adopt the same plotting

\footnotetext{
${ }^{2}$ At that time the IRI used a two-tier forecast system based on the combination of three different SST predictions (from both dynamical and statistical methods and persistence), which they and collaborating institutions used to force a variety of atmosphere GCMs to create a multiscenario, multimodel ensemble used to generate the precipitation forecasts. The atmosphere GCMs are initialized from simulations forced with the prior observed SSTs and do not assimilate observed soil moisture conditions.
} 


\section{ECHAM 4.5}
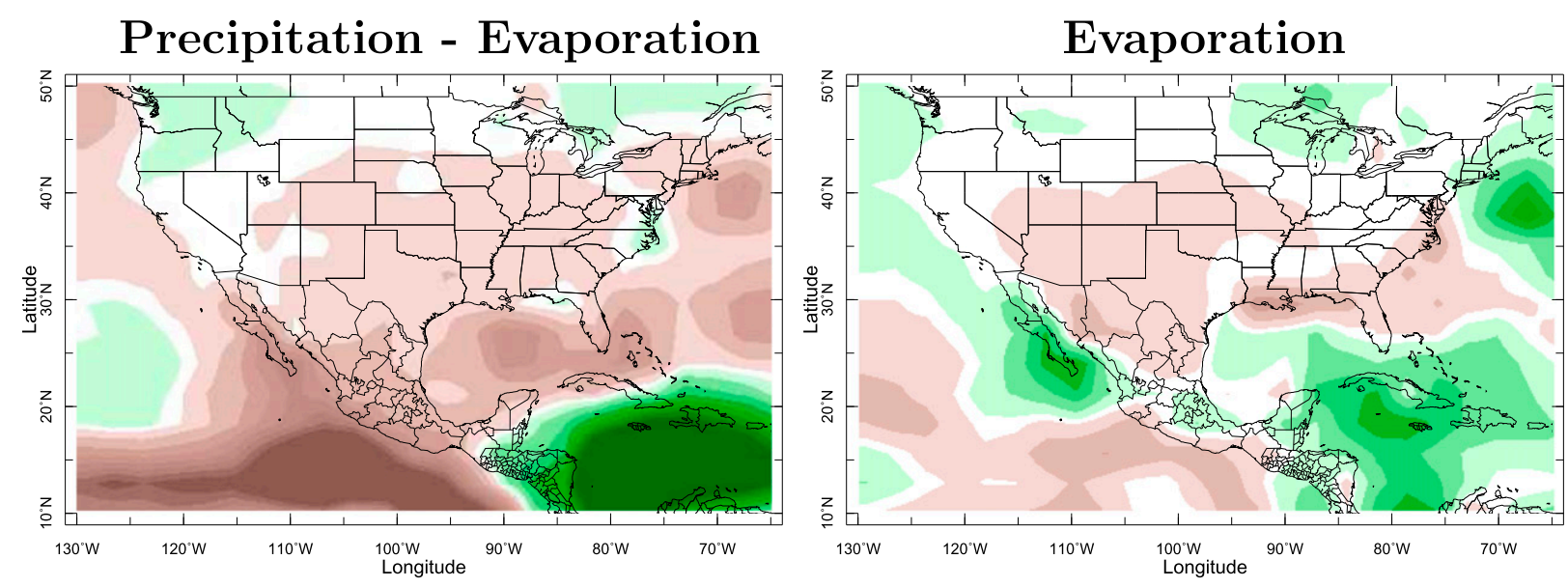

Moisture Convergence
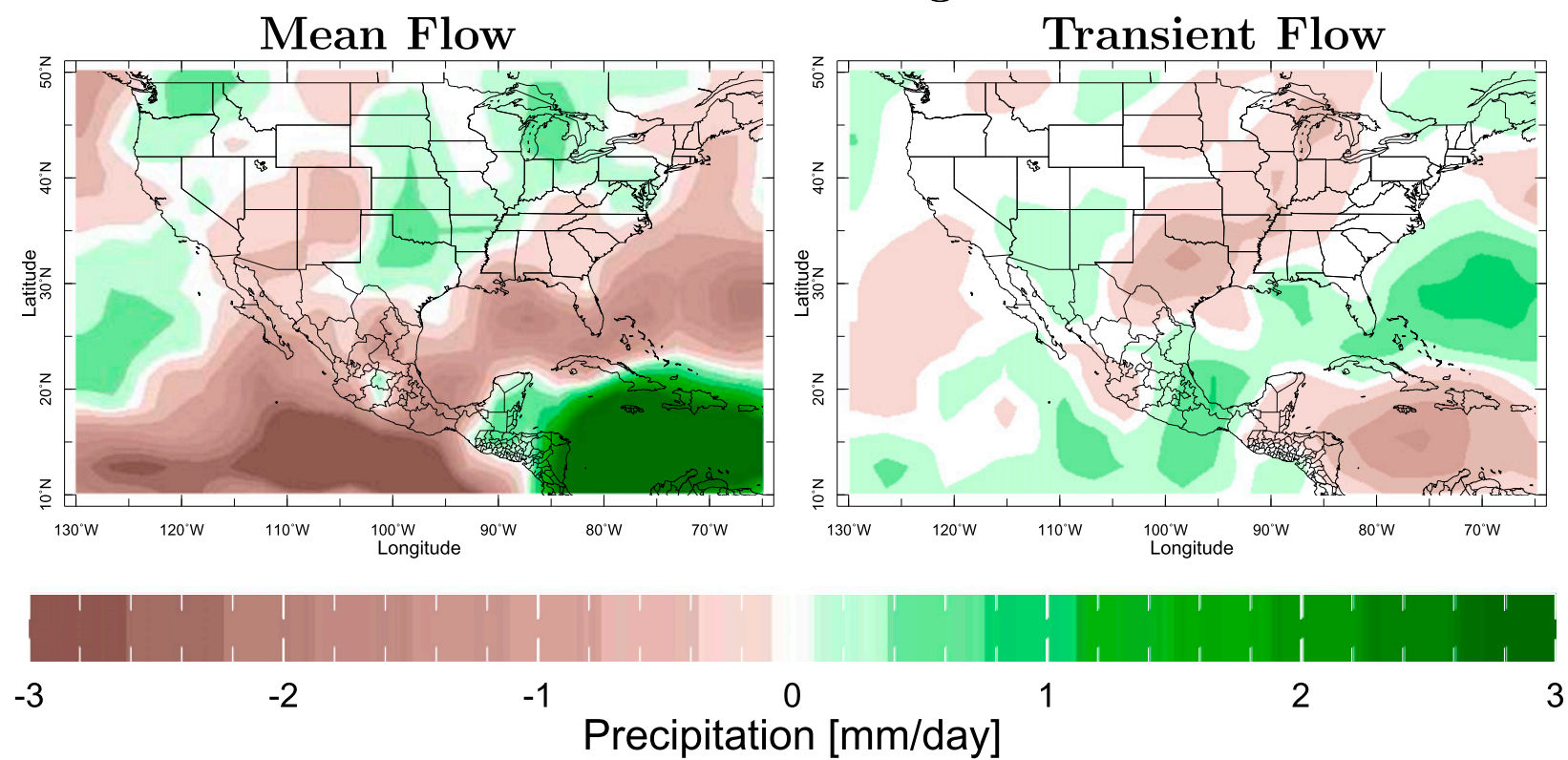

$-3$

$-2$

$-1$

Precipitation [mm/day]

FIG. 10. (Continued)

conventions as for the publicly issued Net Assessment forecasts (i.e., probabilities of precipitation amounts falling within terciles of the distributions) and limit ourselves to a qualitative comparison with what actually occurred. In Figs. 17 and 18 we show the 4-month lead time forecasts of seasonal means from SON 2010 through SON 2011. The La Niña conditions in the Pacific Ocean during winter 2010/11 were quite well forecast with a 3.5-month lead. The warmth of the Atlantic Ocean was, however, not well forecast. The forecast then had the La Niña persist at strength into MAM 2011 whereas in nature the event was already significantly decayed by then (Fig. 4). The forecast did not have the La Niña decay until SON 2011 but by then, in nature, the weakened La Niña had already begun to strengthen.

Turning to the precipitation forecasts, which can be compared to the observations in Fig. 5, there was considerable skill from SON 2010 through MAM 2011. The 4-month forecast for DJF 2010/11 confidently predicted a $40 \%$ to $50 \%$ chance of drier than normal conditions (lowest tercile) across the southern United States and northern Mexico, clearly matching the observed anomaly. The forecast also successfully predicted continued dry conditions in MAM 2011. These precipitation forecasts were driven by the largely successful prediction of La Niña conditions from SON 2010 through MAM 2011. 
Mean flow component
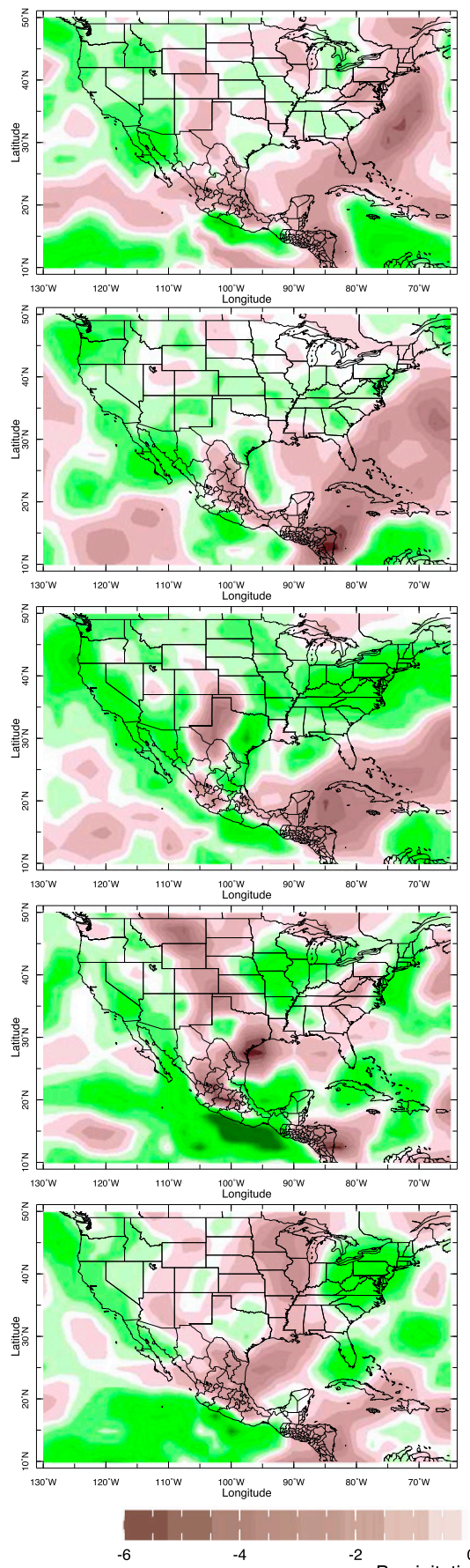

Transient flow component
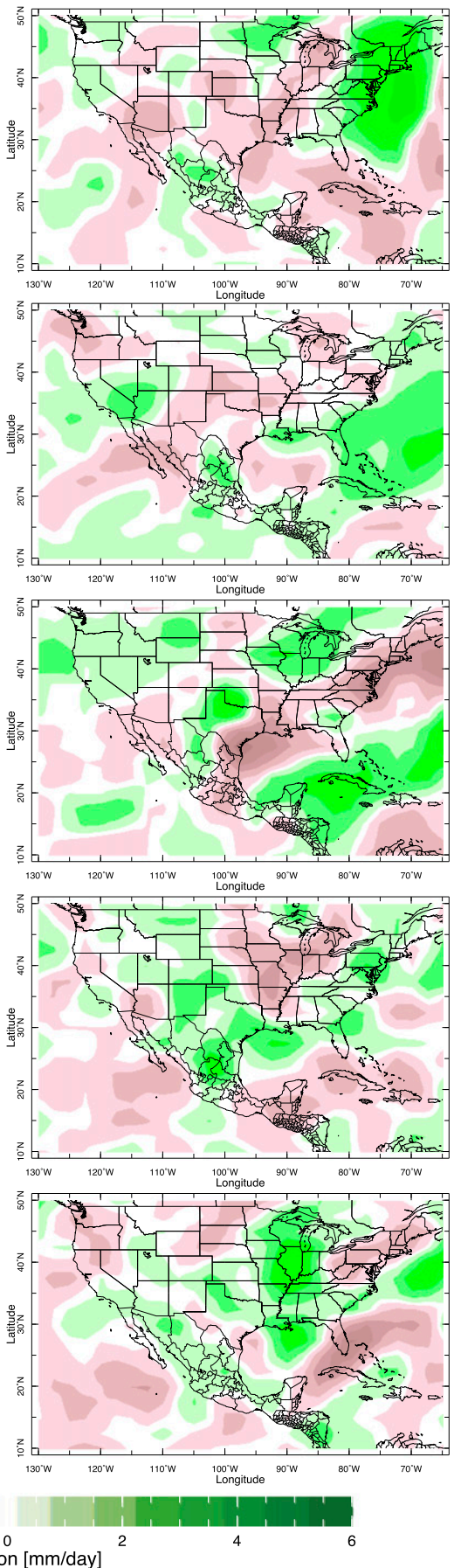

FIG. 11. Anomalies of the convergence of the vertically integrated moisture transport in the NCEP-NCAR Reanalysis due to (left) anomalies in the monthly mean state and (right) the covariance of the submonthly transient states for (top to bottom) seasons from SON 2010 to SON 2011, which is during the 2010/11 TexMex drought. Units are $\mathrm{mm} \mathrm{day}^{-1}$. Note the expanded scale relative to that for Figs. 6-10. 
Conv of vert integrated moisture flux
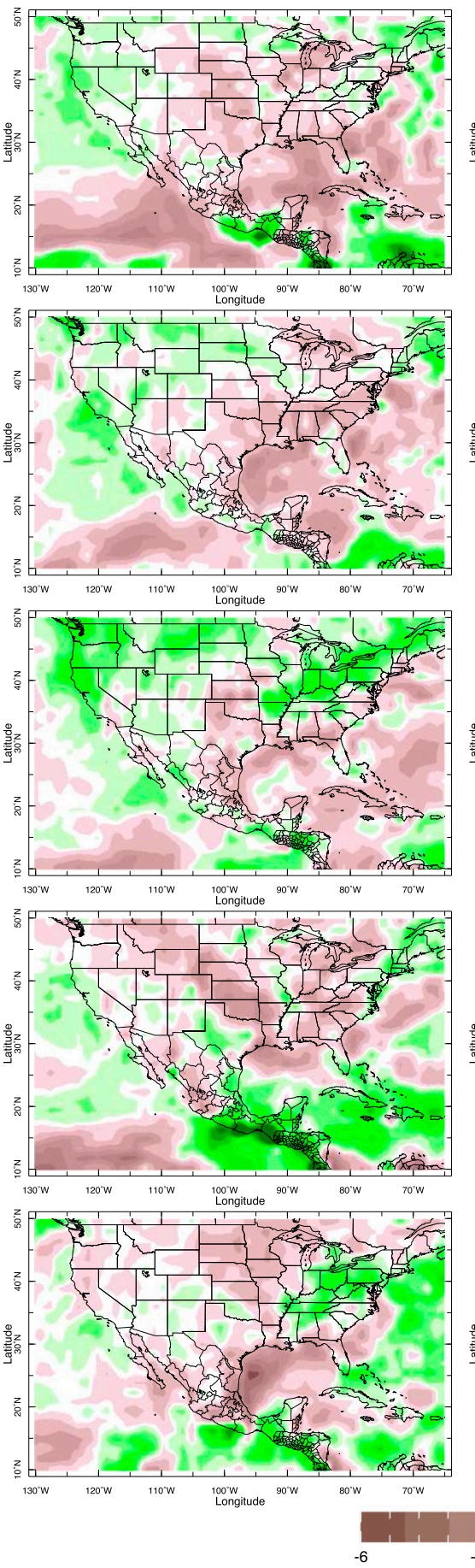

Mean flow component
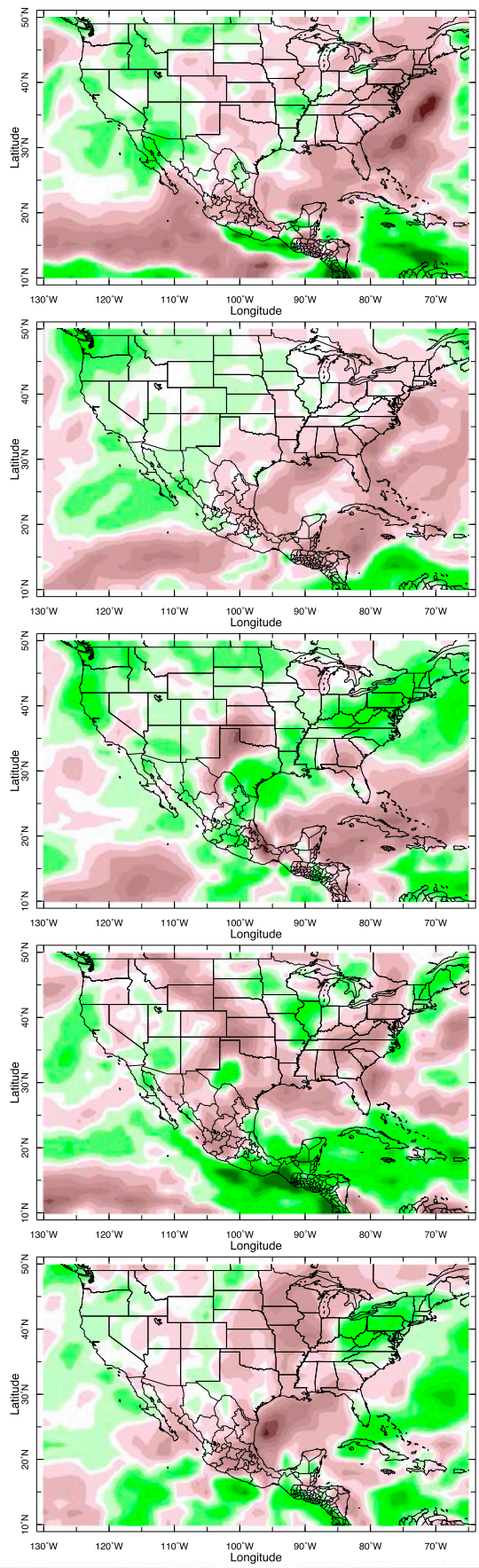

Transient flow component
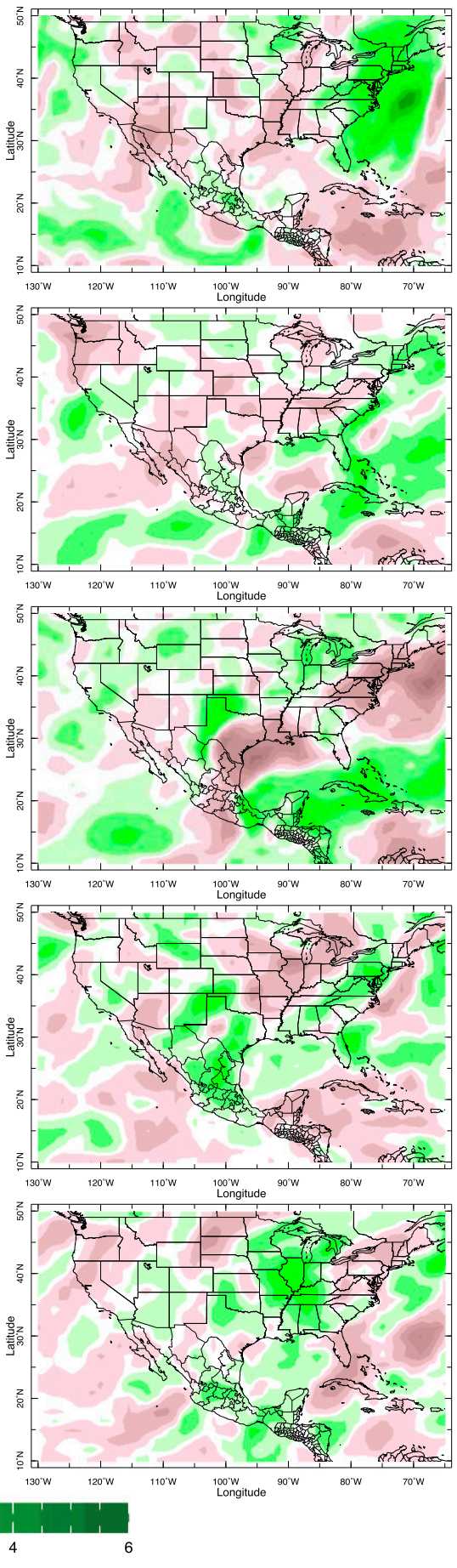

FIG. 12. As in Fig. 11, but using ERA-Interim (relative to a 1979-2011 climatology) and with an additional (left) column showing the anomalies in the convergence of the vertically integrated moisture transports as reported within the ERA-Interim data. The convergence is well approximated by the sum of the mean and transient flow contributions. Units are mm day ${ }^{-1}$. 

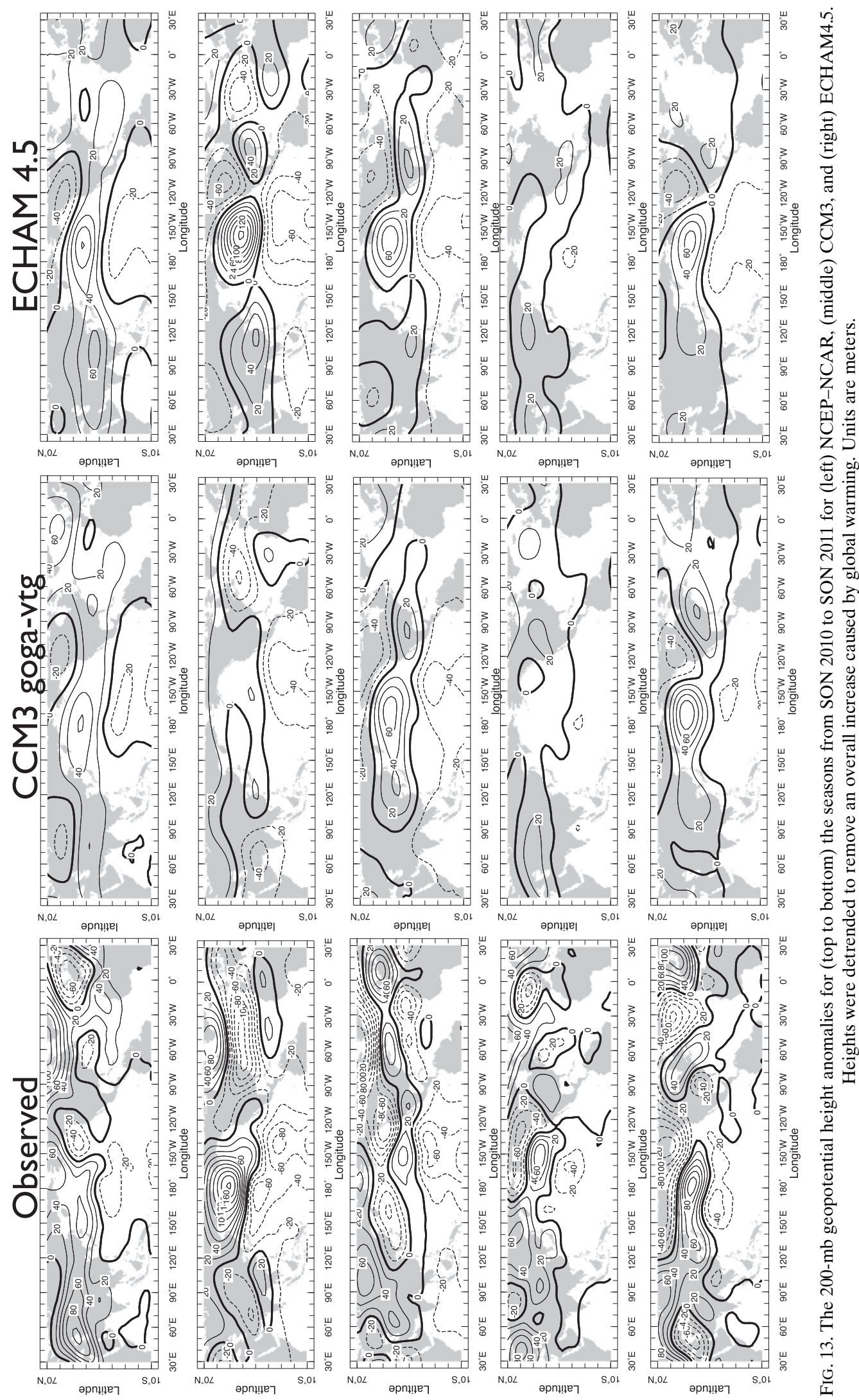


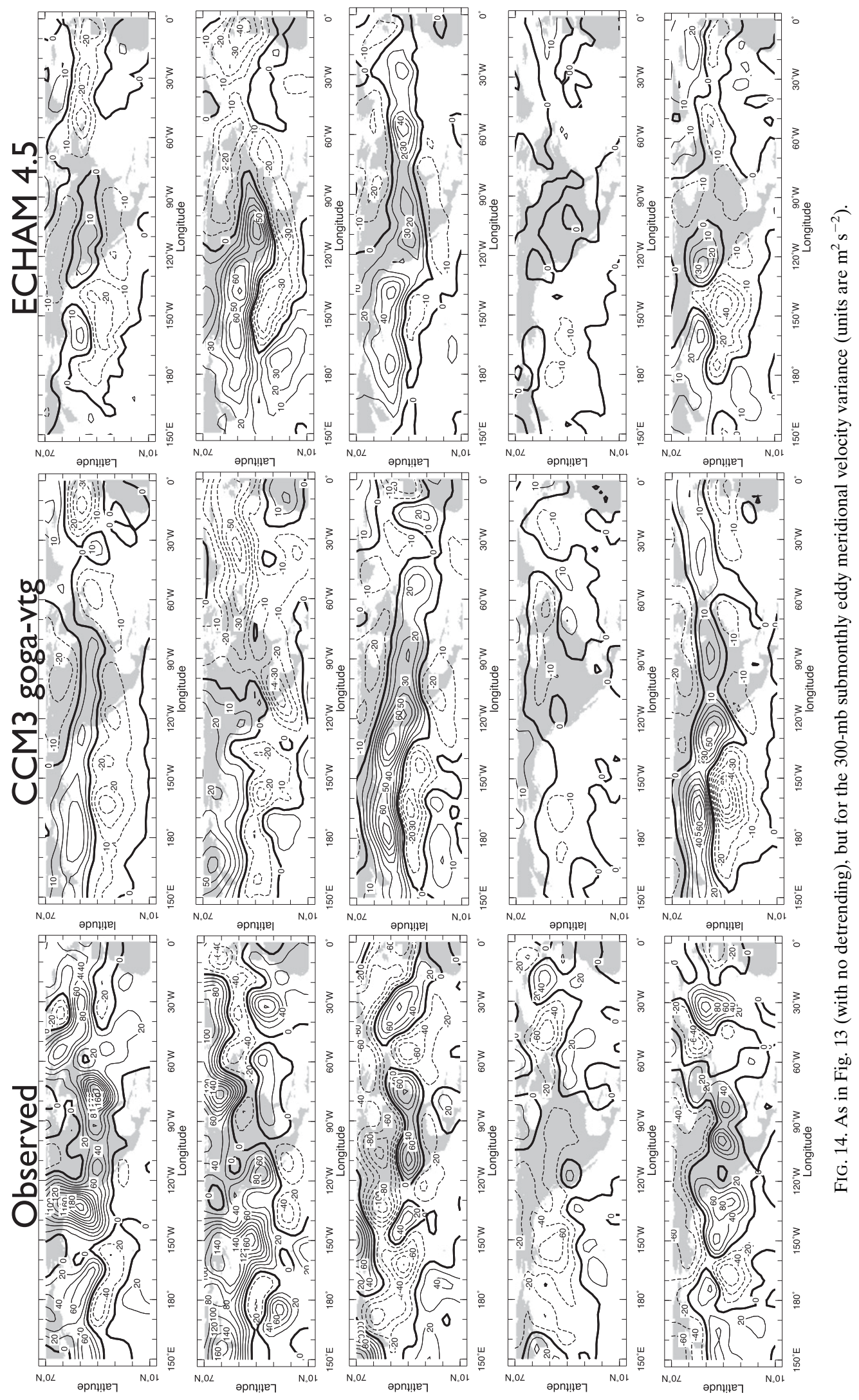



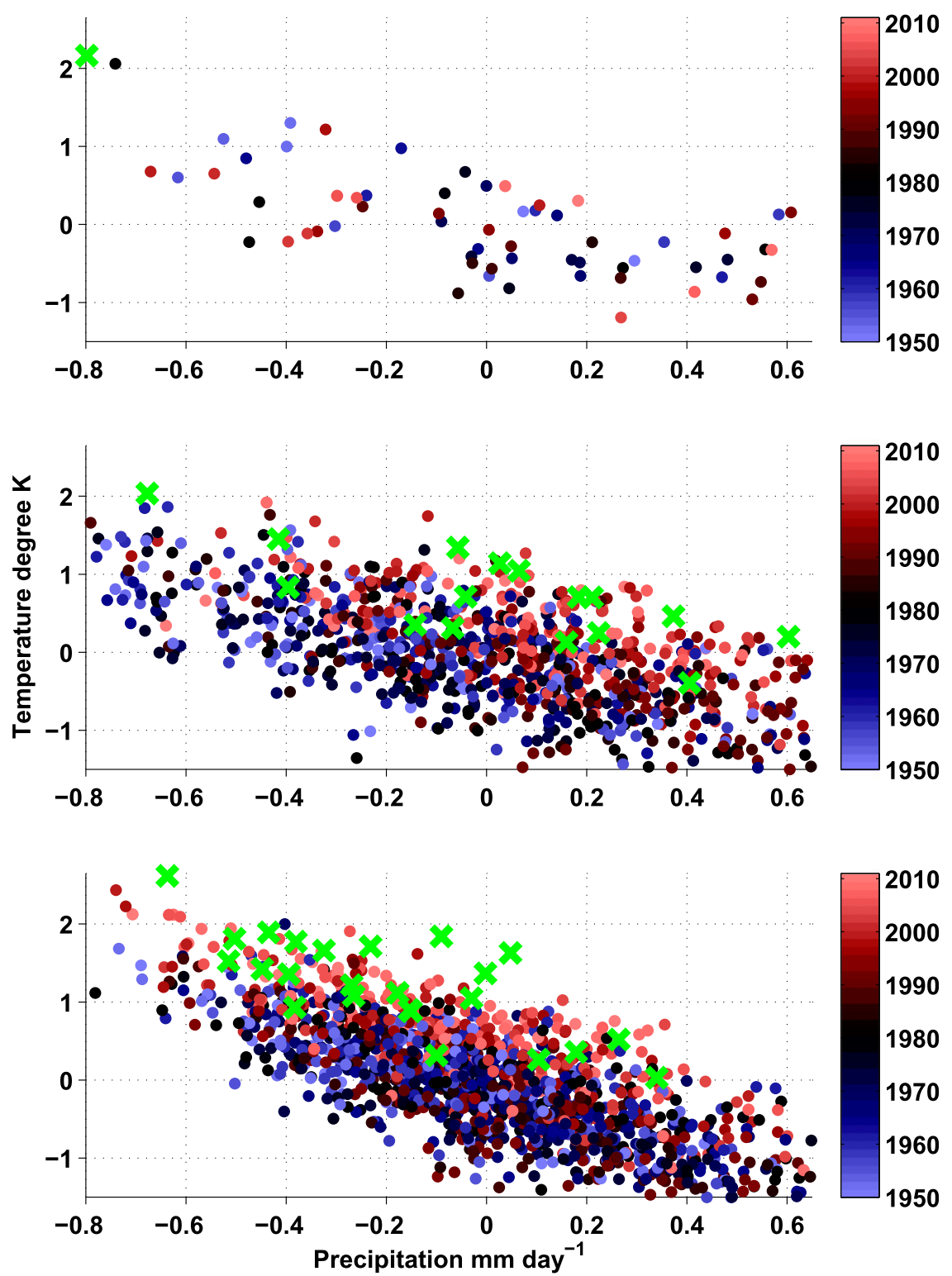

FIG. 15. Scatterplots of JJA temperature (Kelvin) vs precipitation $\left(\mathrm{mm} \mathrm{day}^{-1}\right)$ anomalies for the TexMex region and the 1950-2011 period for (top) observations, (middle) CCM3, and (bottom) ECHAM4.5. The dots have been color coded by year with the scale shown, ranging from light blue in 1950 to light red in 2010 and with the green crosses the values for 2011.

However, as noted in section 6 , the observed precipitation reductions in the southeastern United States seem to have been associated with the negative NAO event and, if so, the forecast skill in that region is partly luck. For JJA 2011, despite the forecast continued La Niña, the precipitation forecast for North America was for climatological amounts, consistent with summer teleconnections being insufficiently robust to provide predictive skill. As such, the forecasts failed to predict the serious near pan-continental drought of summer 2011. As the La Niña redeveloped in SON 2011, and La
Niña conditions were forecast, the seasonal reestablishment of teleconnections transferred this into forecasts of modest likelihood of drier than normal conditions in line with what occurred.

Despite the unsurprising inability to predict the severe dry anomalies of summer 2011 the 4-month forecasts nonetheless warned of an impending and developing drought. If we recall that in summer 2010 the United States was essentially free of drought according to the Drought Monitor, the forecast from spring and summer 2010 that the southern United States and Mexico would 


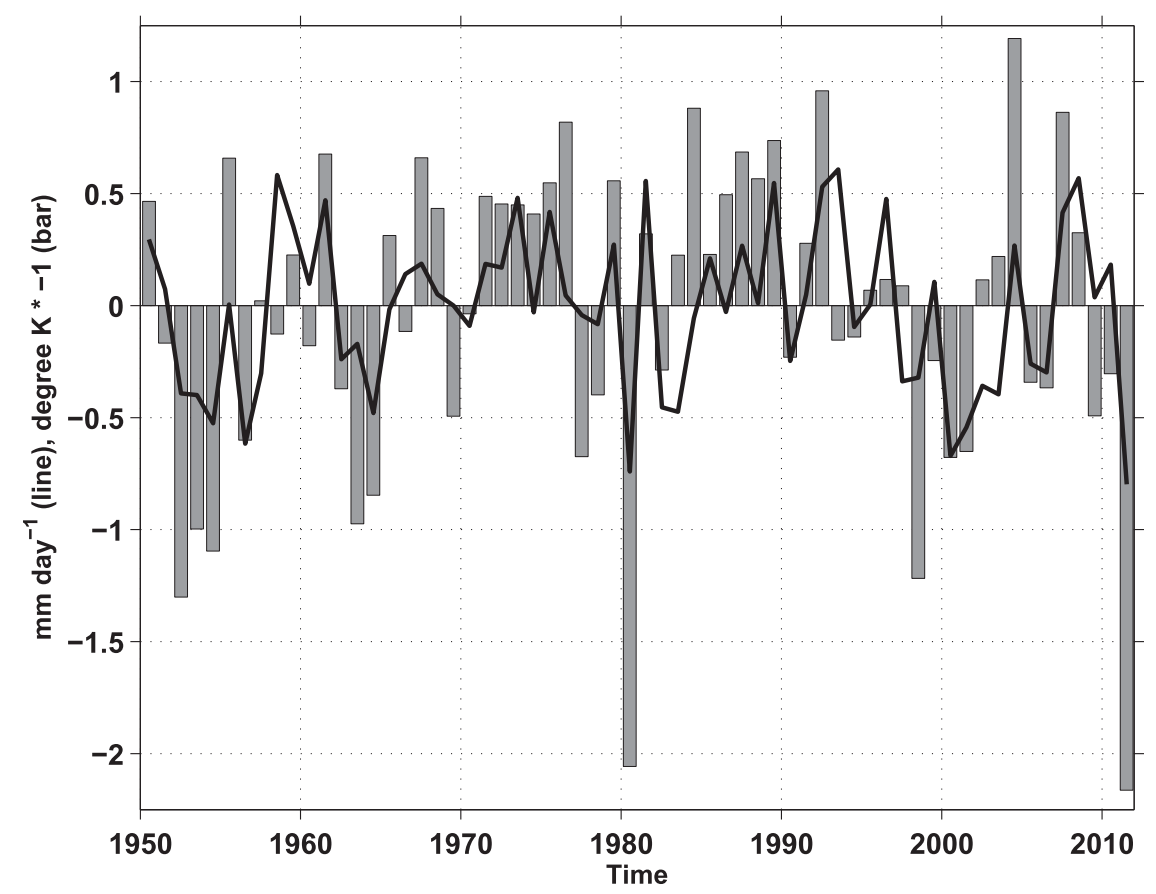

FIG. 16. Time history of observed JJA temperature (bars, K) and precipitation (line, $\mathrm{mm} \mathrm{day}^{-1}$ ) anomalies for the TexMex region and the 1950-2011 period.

immediately move back into drier than normal conditions was prescient and provided useful information, with seasonal forewarning, for any efforts in drought planning.

\section{Conclusions}

We have attempted to determine the causes of the 2010-11 severe drought in North America that was centered on the regions of Texas and northeastern Mexico and that had severe social consequences. Our conclusions are as follows:

- The drought began in fall of 2010 just as a La Niña developed in the tropical Pacific Ocean and was concurrent with La Niña conditions through to fall of 2011 when our analysis ends. Historically, severe and extended droughts in the southwest United States, the Great Plains, and northern Mexico have coincided with La Niña conditions; in that sense, the recent drought appears the latest such event.

- Climate models forced by observed SSTs produced drought conditions across the southern United States and northern Mexico from fall 2010 to spring 2011, which coincides with the seasons when tropical Pacific SSTs are most effective in exciting a teleconnected atmospheric circulation response over North America. In summer 2011 the models' precipitation reductions are much weaker than those observed. Consistent with low teleconnectivity to the tropical Pacific in summer, the modeled precipitation drop appears to be a response to reduced evaporation from the inherited drier surface. Explaining the much larger observed precipitation reduction requires either a large role for internal atmospheric variability or much stronger local landatmosphere interactions than in the models.

- Despite the model support for tropical Pacific SSTs as the cause of the onset and continuation of the drought, detailed analysis of precipitation and mean and transient atmospheric circulation fields provides evidence that the actual drought was also strongly influenced by internal atmospheric variability that caused departures of these patterns from those typically associated with La Niña conditions. For example, during winter 2010/11 a very strong negative NAO event caused northerly and descending flow over the southern Plains and southeast United States inducing drying.

- The decomposed moisture budgets in the models and reanalyses provide better indication of the mechanisms involved in the drought. In the models during winter 2010/11 the drought intensifies over much of the southern United States due to anomalous moisture divergence by transient eddies, which is related to the canonical northward shift of the Pacific-North American storm track expected during La Niña events. In the reanalyses drying by transient eddies is much more spatially diffuse. However, the ERAInterim does show strong drying over Texas and the south central and southeastern United States due to 

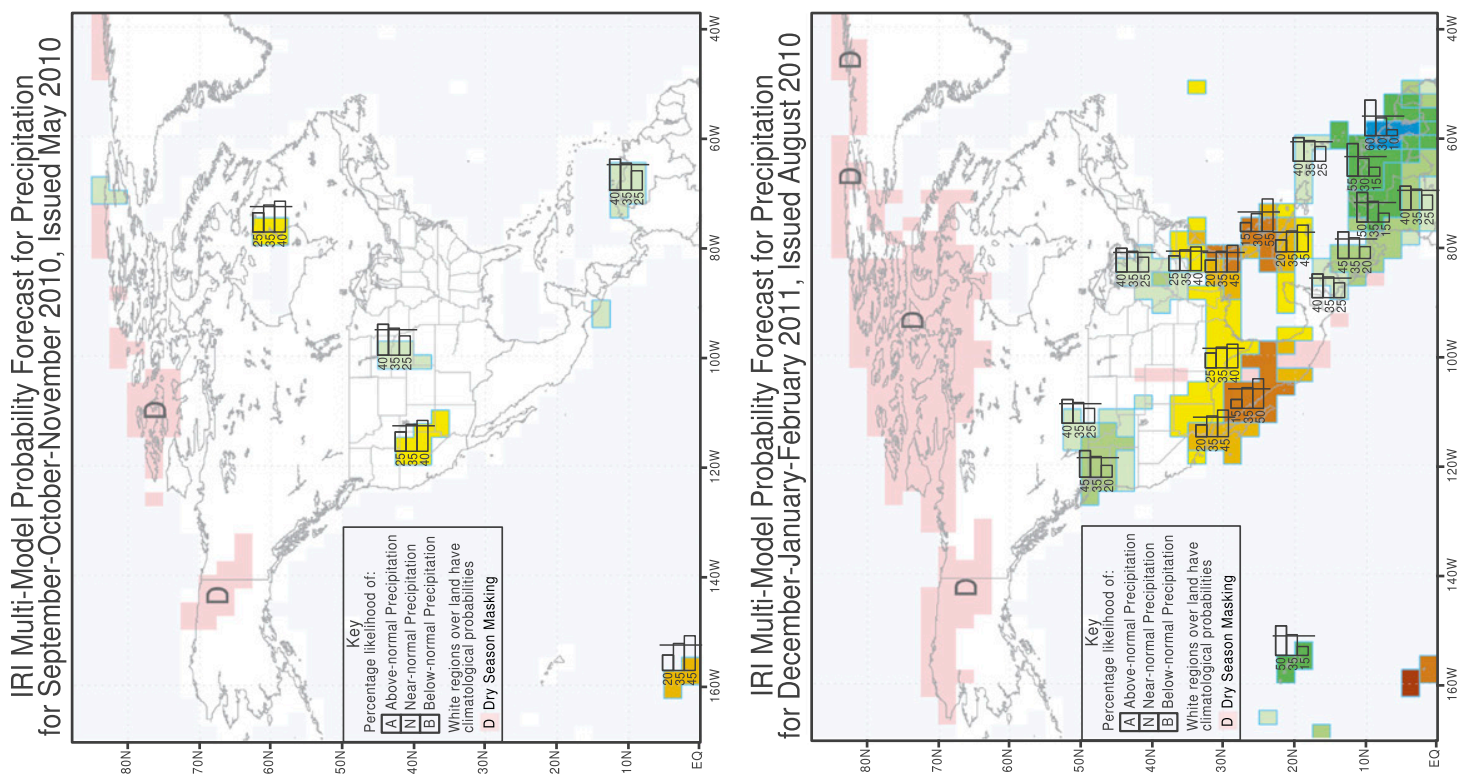

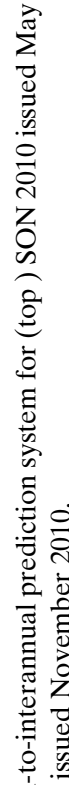
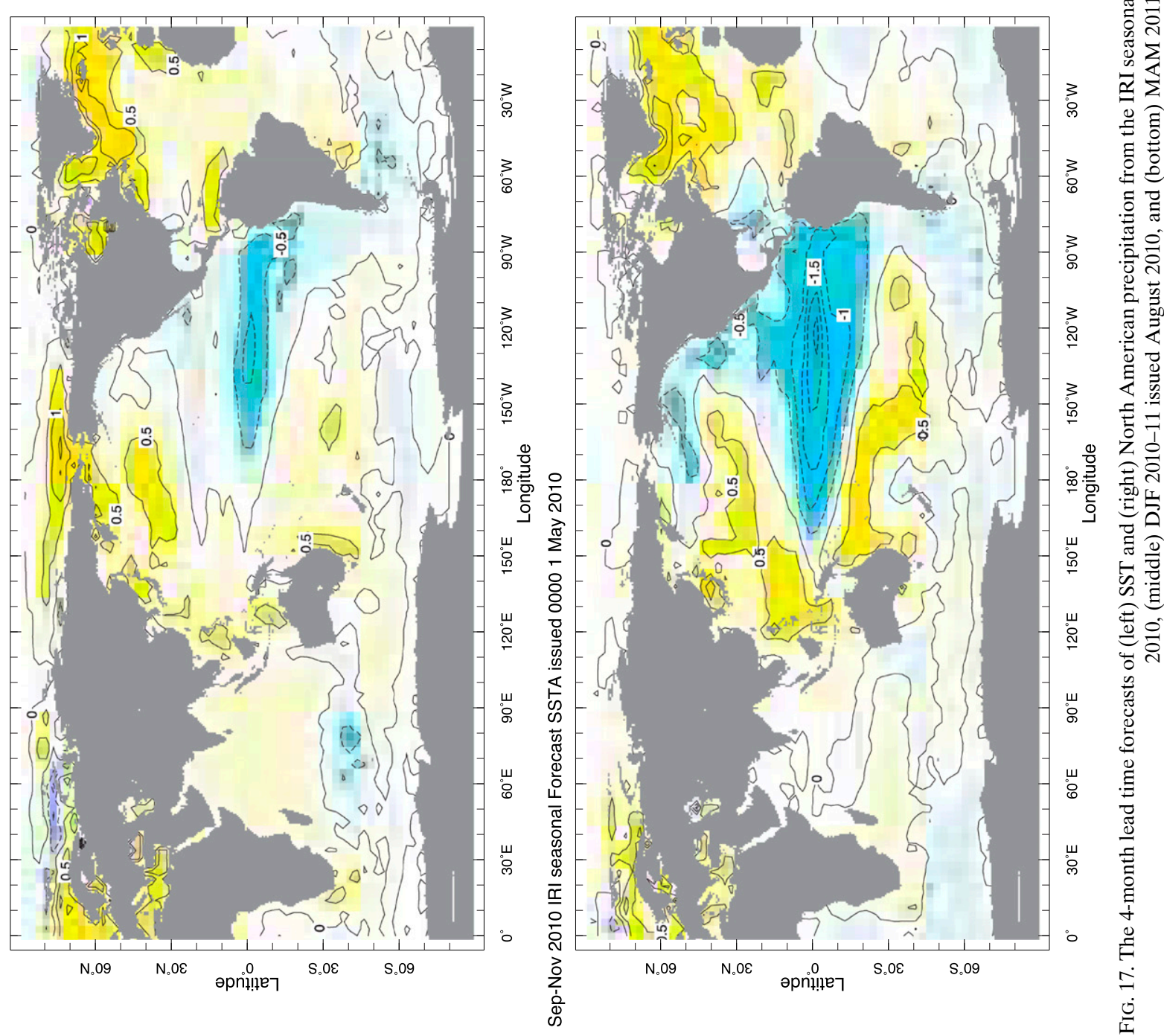

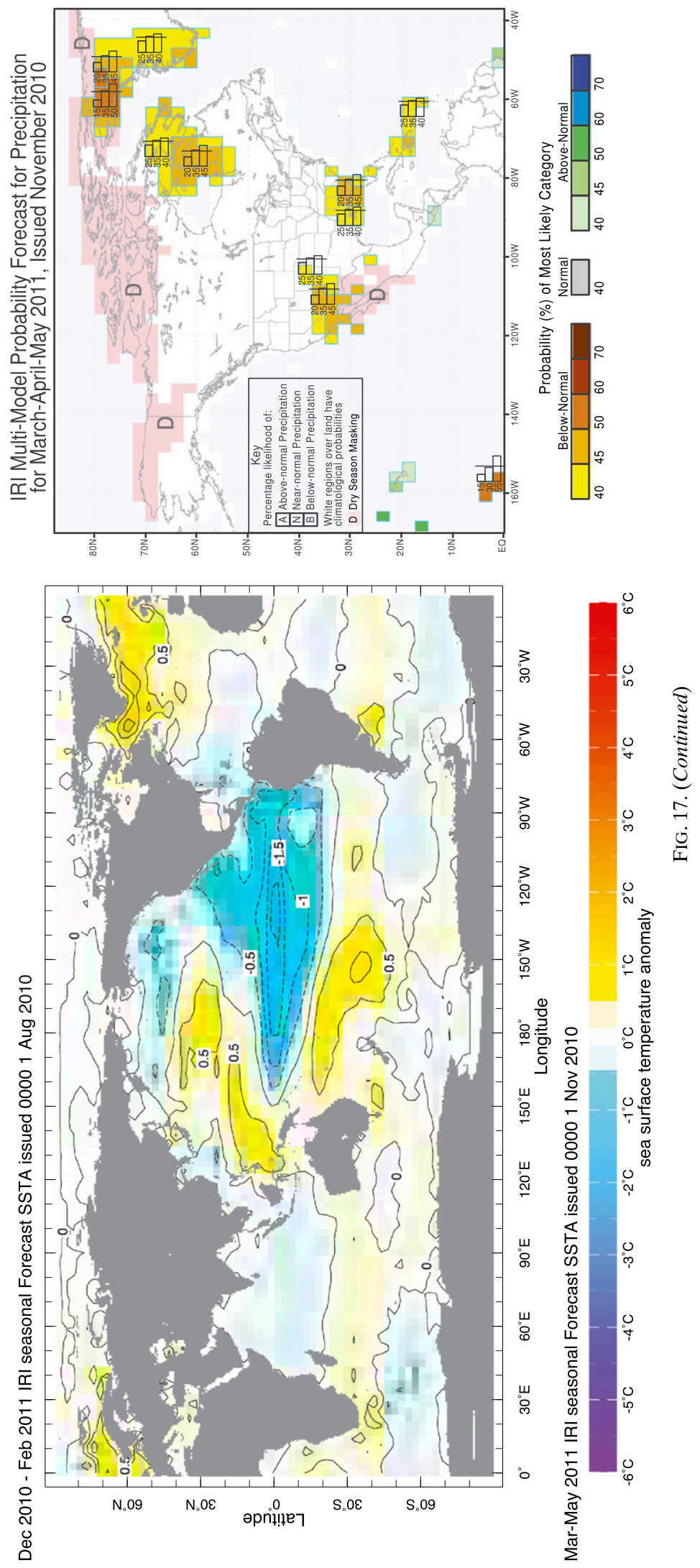

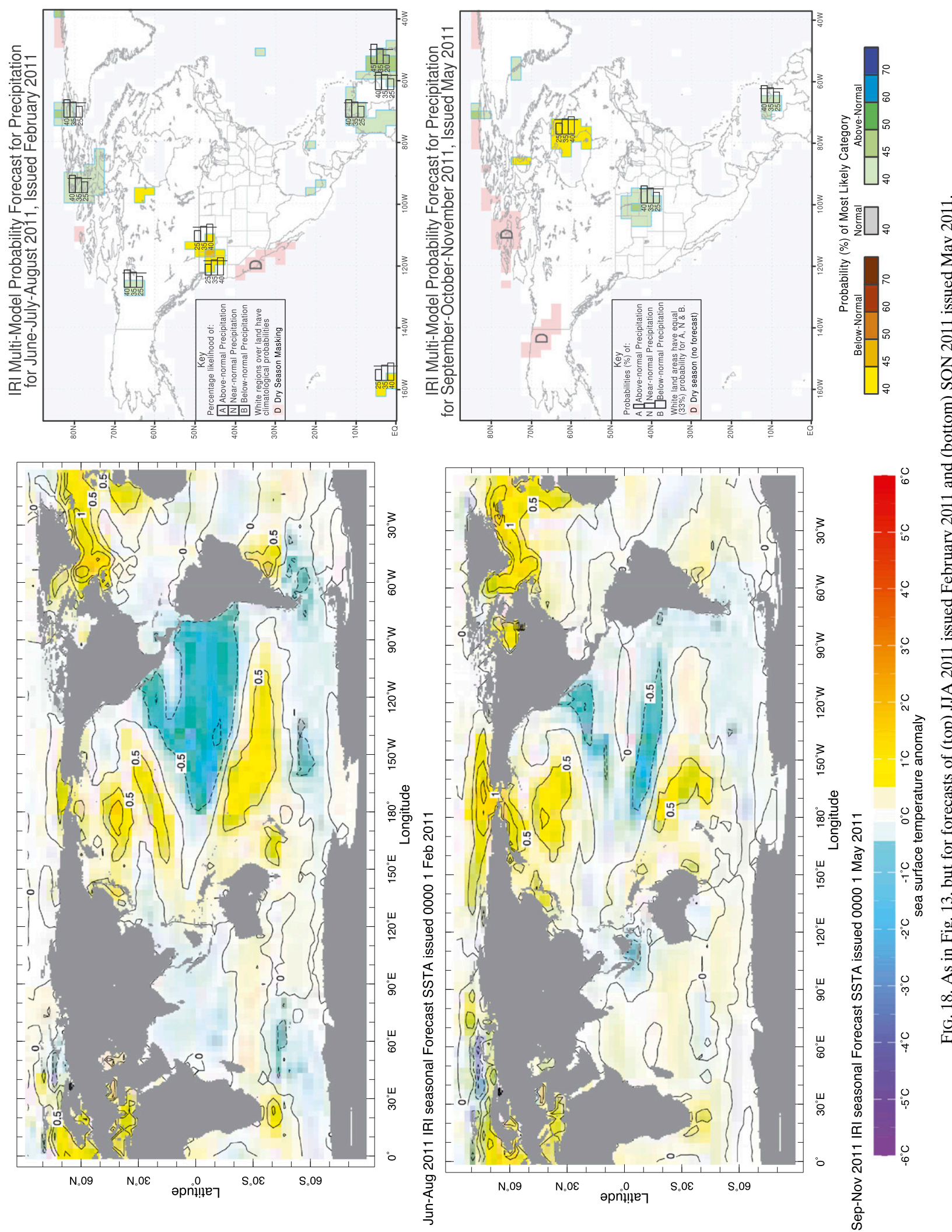

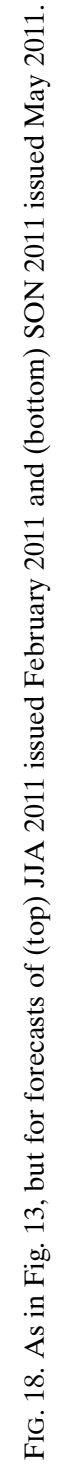


mean flow moisture divergence associated with the negative NAO event. The reanalyses agree that mean flow moisture divergence anomalies sustain the drought in the summer of 2011 but this is not captured by the SST-forced models.

- The inability of the models to reproduce the observed precipitation and circulation anomalies as a consequence of SST forcing alone could be in part a result of model error but also suggests that random internal atmospheric variability played a significant role in the character, timing, and evolution of this particular drought. This limits predictability of the drought, even in the winter season when North America is most influenced by tropical Pacific SST anomalies and even when, as in winter 2010/11, the SST anomalies were strong. Continuation of the drought into summer 2011 appears unpredictable in terms of the weakening $\mathrm{La}$ Niña SST anomalies and could have arisen also from random internal atmospheric variability. However, the role of soil moisture-atmosphere interactions should also be examined and whether these are adequately captured in climate models.

- Real-time predictions performed by the IRI did successfully predict drought over the southern United States and northern Mexico to develop in SON 2010 and to intensify and persist through MAM 2011, which was based on successful forecasts of La Niña conditions. However, given the role of the NAO in the observed winter 2010/11 drought, the mechanisms of the forecast drought probably differed in details from the actual drought. The SST forecasts continued the La Niña into summer 2011 but this did not translate into a forecast of a negative precipitation anomaly and hence drought intensification was not forecast. However, since the ECHAM4.5 hindcasts produced a modest precipitation reduction in JJA 2011 sustained by reduced evaporation, and the NCEP model hindcasts of Hoerling et al. (2013) did likewise, it is worth examining if, in nature, land surface-atmosphere coupling, or some unclear SST forcing, helped intensify the drought.

- The high (and record breaking) surface air temperatures during summer 2011 in the TexMex region are consistent with the very dry conditions and the general and clear inverse relation between precipitation and temperature in the region over past decades. Summer 2011 appears as extreme in terms of its dryness and warmth but not necessarily outside the range expected from this relation alone.

The 2010/11 drought extended through 2012 with another summer of record-breaking heat and drought as well as the extension of the drought into both the
Southwest and Midwest. La Niña conditions also persisted from 2011 to 2012 before fading in summer of 2012 (although most of Texas remains in drought at the time of writing in June 2013). Follow-up work will be needed to assess the cause of the 2011/12 drought but as for the prior year, a combination of SST-forced and internally generated atmospheric circulation and moisture budget anomalies is likely the cause. The possibility that temperature records have been broken because background global warming is adding on to the high temperatures caused by dry conditions also needs to be addressed (Hoerling et al. 2013). In terms of seasonal-to-interannual prediction, successful prediction of tropical Pacific SSTs can enable a prediction of emerging or continuing dry conditions during the Northern Hemisphere fall, winter, and spring seasons. However, extremes are rarely, if ever, predicted as a most likely outcome. Nonetheless, the summer drought conditions appeared essentially unpredictable with current prediction systems. It should be remembered that in some cases atmospheric variability will offset the impacts of SST-forced anomalies; in other cases they will enhance the SST-forced anomalies. However, in the case of 2010/11, the combination of La Niña conditions and internal atmospheric variability led to a drought that was severe, much worse in terms of dryness and heat than that forecast ahead of time and at the very edge of the observed historical variability of climate.

Acknowledgments. This work was supported by NOAA Awards NA08OAR4320912 and NA10OAR4310137 (Global Decadal Hydroclimate Variability and Change) and NSF Award AGS-0804107. The authors thank Yochanan Kushnir for useful discussions, Shuhua Li for help with the IRI forecast data, and three anonymous reviewers for helpful comments and suggestions.

\section{REFERENCES}

Barnston, A., S. Li, S. J. Mason, D. G. DeWitt, L. Goddard, and X. Gong, 2010: Verification of the first 11 years of IRI's seasonal climate forecasts. J. Appl. Meteor. Climatol., 49, 493520 .

Cayan, D., T. Das, D. Pierce, T. Barnett, M. Tyree, and A. Gershunov, 2010: Future dryness in the southwest United States and the hydrology of the early 21 st century drought. Proc. Natl. Acad. Sci. USA, 107, 21 271-21276, doi:10.1073/pnas.0912391107.

Chen, M., P. Xie, J. E. Janowiak, and P. A. Arkin, 2002: Global land precipitation: A 50-yr monthly analysis based on gauge observations. J. Hydrometeor., 3, 249-266.

Cook, B., R. Miller, and R. Seager, 2008: Dust and sea surface temperature forcing of the 1930s "Dust Bowl" drought. Geophys. Res. Lett., 35, L08710, doi:10.1029/2008GL033486.

, - , and - 2009: Amplification of the North American Dust Bowl drought through human-induced land degradation. Proc. Natl. Acad. Sci. USA, 106, 4997-5001, doi:10.1073/ pnas.0810200106. 
R. Seager, and R. Miller, 2010: Atmospheric circulation anomalies during two persistent North American droughts: 1932-1939 and 1948-1957. Climate Dyn., 36, 2339-2355, doi:10.1007/s00382-010-0807-1.

Dee, D., and Coauthors, 2011: The ERA-Interim Reanalysis: Configuration and performance of the data assimilation system. Quart. J. Roy. Meteor. Soc., 137, 553-597, doi:10.1002/ qj. 828.

Herweijer, C., R. Seager, and E. R. Cook, 2006: North American droughts of the mid to late nineteenth century: A history, simulation and implication for mediaeval drought. Holocene, 16, 159-171, doi:10.1191/0959683606hl917rp.

Hoerling, M. P., X.-W. Quan, and J. Eischeid, 2009: Distinct causes for two principal U.S. droughts of the 20th century. Geophys. Res. Lett., 36, L19708, doi:10.1029/2009GL039860.

- and Coauthors, 2013: Anatomy of an extreme event. J. Climate, 26, 2811-2832.

—, J. Eischeid, A. Kumar, R. Leung, A. Mariotti, K. Mo, S. Schubert, and R. Seager, 2014: Causes and predictability of the 2012 Great Plains drought. Bull. Amer. Meteor. Soc., in press.

Jin, E. K., and Coauthors, 2008: Current status of ENSO prediction skill in coupled ocean-atmosphere models. Climate Dyn., 31, 647-664, doi:10.1007/s00382-008-0397-3.

Kalnay, E., and Coauthors, 1996: The NCEP/NCAR 40-Year Reanalysis Project. Bull. Amer. Meteor. Soc., 77, 437-471.

Kaplan, A., M. A. Cane, Y. Kushnir, A. C. Clement, M. B. Blumenthal, and B. Rajagopalan, 1998: Analyses of global sea surface temperature: 1856-1991. J. Geophys. Res., 103 (C9), 18567-18589.

Kistler, R., and Coauthors, 2001: The NCEP-NCAR 50-Year Reanalysis: Monthly means CD-ROM and documentation. Bull. Amer. Meteor. Soc., 82, 247-267.

Kumar, A., and M. P. Hoerling, 1998: Annual cycle of PacificNorth American seasonal predictability associated with different phases of ENSO. J. Climate, 11, 3295-3308.

Madden, R. A., and J. Williams, 1978: The correlation between temperature and precipitation in the United States and Europe. Mon. Wea. Rev., 106, 142-147.

Mason, S., and L. Goddard, 2001: Probabilistic precipitation anomalies associated with ENSO. Bull. Amer. Meteor. Soc., 82, 619-638.

Mueller, B., and S. I. Seneviratne, 2012: Hot days induced by precipitation deficits at the global scale. Proc. Natl. Acad. Sci. USA, 109, 12398-12403.

Nielsen-Gammon, J., 2012: The 2011 Texas drought. Texas Water $J ., 3,59-95$. [Available online at http://journals.tdl.org/twj/ index.php/twj/article/view/6463.]

Rayner, N., D. Parker, E. Horton, C. Folland, L. Alexander, D. Rowell, E. Kent, and A. Kaplan, 2003: Global analyses of sea surface temperature, sea ice, and night marine air temperature since the late nineteenth century. J. Geophys. Res., 108, 4407, doi:10.1029/2002JD002670.

Roeckner, E. K., and Coauthors, 1996: The atmospheric general circulation model ECHAM-4: Model description and simulation of present day climate. MPI Tech. Rep. 218, 90 pp.

Ropelewski, C. F., and M. S. Halpert, 1986: North American precipitation and temperature patterns associated with the El Niño/Southern Oscillation. Mon. Wea. Rev., 114, 2352-2362.

Schubert, S. D., M. J. Suarez, P. J. Pegion, R. D. Koster, and J. T. Bacmeister, 2004a: Causes of long-term drought in the United States Great Plains. J. Climate, 17, 485-503. $-\ldots,-,-, \ldots$, and,$- 2004 \mathrm{~b}$ : On the cause of the 1930s Dust Bowl. Science, 303, 1855-1859, doi:10.1126/ science.1095048.

— , and Coauthors, 2009: A U.S. CLIVAR project to assess and compare the responses of global climate models to droughtrelated SST forcing patterns: Overview and results. J. Climate, 22, 5251-5272.

Seager, R., 2007: The turn of the century North American drought: Global context, dynamics, and past analogs. J. Climate, 20, 5527-5552.

_ , and G. A. Vecchi, 2010: Greenhouse warming and the 21st century hydroclimate of southwestern North America. Proc. Natl. Acad. Sci. USA, 107, 21277-21282, doi:10.1073/ pnas.0910856107.

- , and N. Henderson, 2013: Diagnostic computation of moisture budgets in the ERA-Interim reanalysis with reference to analysis of CMIP-archived atmospheric model data. $J$. Climate, 26, 7876-7901.

_ N. Harnik, Y. Kushnir, W. Robinson, and J. Miller, 2003: Mechanisms of hemispherically symmetric climate variability. J. Climate, 16, 2960-2978.

,-- W. A. Robinson, Y. Kushnir, M. Ting, H. P. Huang, and J. Velez, 2005a: Mechanisms of ENSO-forcing of hemispherically symmetric precipitation variability. Quart. J. Roy. Meteor. Soc., 131, 1501-1527, doi:10.1256/qj.04.96.

— Y. Y. Kushnir, C. Herweijer, N. Naik, and J. Velez, 2005b: Modeling of tropical forcing of persistent droughts and pluvials over western North America: 1856-2000. J. Climate, 18, 4065-4088.

— - and Coauthors, 2007: Model projections of an imminent transition to a more arid climate in southwestern North America. Science, 316,1181-1184, doi:10.1126/science.1139601. , Y. Kushnir, M. Ting, M. A. Cane, N. Naik, and J. Velez, 2008: Would advance knowledge of 1930s SSTs have allowed prediction of the Dust Bowl drought? J. Climate, 21, 3261-3281.

_ modeling and tree ring study of variability and climate change. Atmósfera, 22, 1-31.

_ , N. Naik, M. A. Cane, N. Harnik, M. Ting, and Y. Kushnir, 2010a: Adjustment of the atmospheric circulation to tropical Pacific SST anomalies: Variability of transient eddy propagation in the Pacific-North America sector. Quart. J. Roy. Meteor. Soc., 136, 277-296.

and G. A. Vecchi, 2010b: Thermodynamic and dynamic mechanisms for large-scale changes in the hydrological cycle in response to global warming. J. Climate, 23, 4651-4668.

Solomon, S., D. Qin, M. Manning, Z. Chen, M. Marquis, K. Averyt, M. Tignor, and H. L. Miller Jr., Eds., 2007: Climate Change 2007: The Physical Science Basis. Cambridge University Press, 996 pp.

Stahle, D. W., and M. K. Cleaveland, 1988: Texas drought history reconstructed and analyzed from 1698 to 1980 . J. Climate, 1, $59-74$.

_- and Coauthors, 2009: Early 21st century drought in Mexico. Eos, Trans. Amer. Geophys. Union, 90, 89-90, doi:10.1029/ 2009EO110001.

Straus, D. M., and J. Shukla, 2002: Does ENSO force the PNA? J. Climate, 15, 2340-2358.

Ting, M., and H. Wang, 1997: Summertime U.S. precipitation variability and its relation to Pacific sea surface temperatures. J. Climate, 10, 1853-1873. 